\title{
Advances and Challenges in the Molecular Characterization of Petroporphyrins
}

\author{
Amy M. McKenna ${ }^{\dagger}{ }^{*}$, Martha L. Chacón-Patiño ${ }^{\dagger}$, Germain Salvato \\ Vallverdu $^{\dagger}, \S$, Brice Bouyssiere ${ }^{\ddagger}$, , Pierre Giusti, $*, \S, \nabla$ Carlos Afonso $^{\S, \nabla}$, Quan Shi \\ 0 , and Marianny Y. Combariza ${ }^{\perp}$ \\ ${ }^{\dagger}$ National High Magnetic Field Laboratory, Florida State University, 1800 East Paul Dirac Dr., \\ Tallahassee, Florida 32310-4005, United States \\ †Université de Pau et des Pays de l'Adour, E2S UPPA, CNRS, IPREM, UMR5254, Pau, France \\ $\S$ International Joint Laboratory C2MC, Complex Matrices Molecular Characterization, Total \\ Research \& Technology, Gonfreville, BP 27, F-76700 Harfleur, France \\ $\|_{\text {Total Research \& Technology, Gonfreville, BP 27, F-76700 Harfleur, France }}$

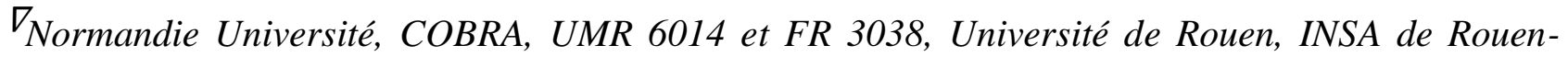 \\ Normandie, CNRS, IRCOF, Mont Saint Aignan Cedex

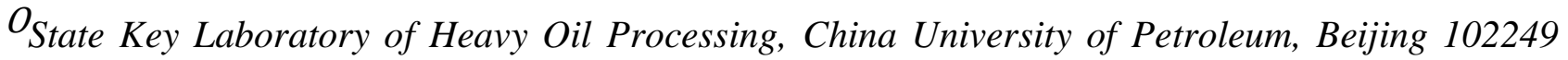 \\ China \\ ${ }^{\perp}$ Escuela de Química, Universidad Industrial de Santander, Bucaramanga, 680002, Colombia
}

Submitted to Energy Fuels (Special issue MS \# ef-2021-xxxx): $\quad$ June 2021

\section{ABSTRACT}

Petroporphyrins, geoporphyrins, or metalloporphyrins are the original petroleum biomarkers, identified by Alfred Treibs more than a century ago and the first molecular evidence for the biogenic origins of petroleum. Since discovery, analytical strategies have been developed to identify porphyrins in petroleum and its fractions. This review focuses on the advances enabled by ultrahigh resolving power Fourier transform ion cyclotron resonance mass spectrometry in tribute to Professor Alan G. Marshall.

Keywords: petroporphyrins, vanadyl porphyrins, nickel porphyrins, geoporphyrins, mass spectrometry, asphaltenes, FT-ICR MS 


\section{ロ INTRODUCTION}

Petroporphyrins, geoporphyrins, or metalloporphyrins, together with other biomarker molecules, elucidate the processes and geological conditions that dictate the molecular structure and composition of crude oil compounds. ${ }^{1-5}$ Nickel, copper, vanadium, iron, and manganese porphyrins are tetrapyrrole-based metal complexes derived from chlorophylls and biologically active light- and oxygen-capturing molecules and are commonly found in fossil fuels (e.g., crude oils, bitumen, and oil sands), with nickel and vanadyl porphyrins commonly referred to as petroporphyrins. ${ }^{6}$ Since the discovery of petroporphyrins by Alfred Treibs in the early 1930s, which provided the first molecular evidence for the biogenic origins of petroleum, many analytical techniques have been applied to characterize petroporphyrins (Treibs hypothesis). ${ }^{1,4,5,7-11}$ Petroporphyrins (e.g., nickel and vanadium) are geochemical marker molecules that contain information about fossil fuel genesis and are critical compounds with oil refinement to determine catalyst performance. ${ }^{12-16}$ The molecular structures of nickel and vanadyl petroporphyrins result from geochemical modifications to the original chlorophyll core (Figure 1, top row) caused by the mineral matrix, organic matter composition, and source rock conditions during early diagenesis and catagenesis (Figure 1) ${ }^{16}$ including phytol loss, demetallation, aromatization by temperature and pressure, peripheral ring attachment, sulfur insertion, $\mathrm{Ni} / \mathrm{V}$ derivatization, and finally transalkylation, commonly associated with thermal conversion and degradation during catagenesis. ${ }^{17}$ Molecular transformations yield a range of structurally diverse porphyrin families that correspond to $\mathrm{N}_{4} \mathrm{VO}, \mathrm{N}_{4} \mathrm{VO}_{2}, \mathrm{~N}_{4} \mathrm{VO}_{3}, \mathrm{~N}_{4} \mathrm{VOS}$, and $\mathrm{N}_{4} \mathrm{Ni}$, depending on the peripheral functional groups, as shown in Figure 1 (bottom row). ${ }^{13,16}$

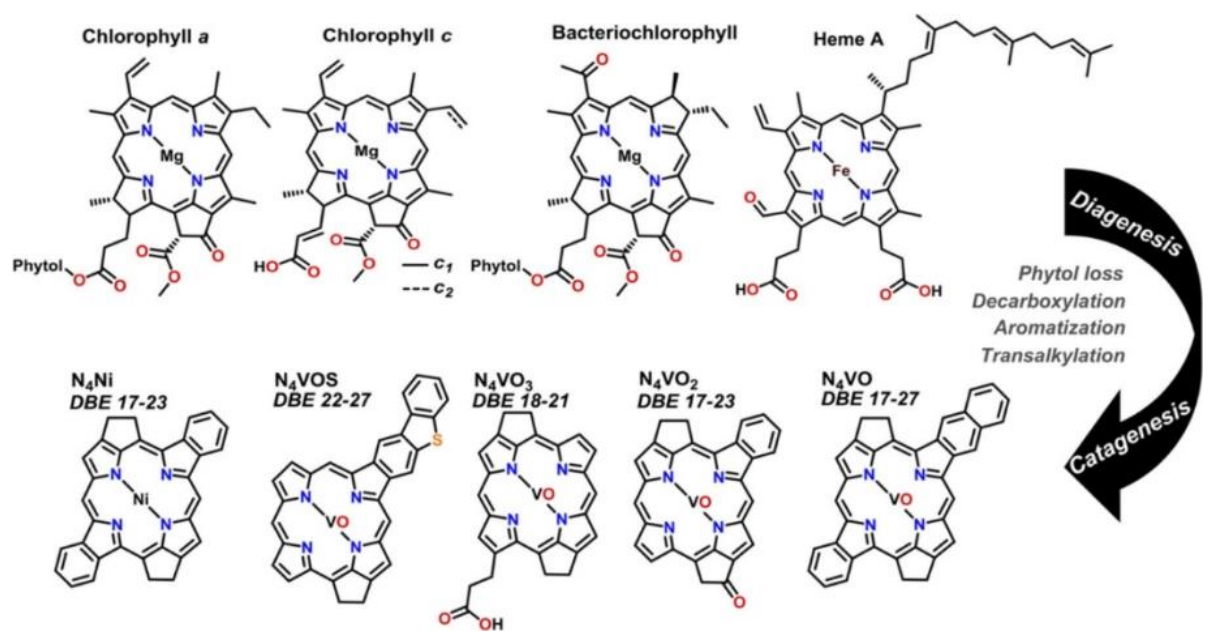

Figure 1. Geochemical transformations of chlorophylls. Diagenesis involves phytol loss, decarboxylation, aromatization, metalation/demetallation, and heteroatom insertion; catagenesis involves thermally induced transalkylation and degradation. ${ }^{16}$ Reproduced from Ramírez-Pradilla, J. S.; Blanco-Tirado, C.; Hubert-Roux, M.; Giusti, P.; Afonso, C.; Combariza, M. Y., Comprehensive Petroporphyrin Identification in Crude Oils Using Highly Selective Electron Transfer Reactions in MALDI-FTICRMS. Energy Fuels 2019, 33, (5), 3899-3907. Copyright 2019 American Chemical Society.

Very early, mass spectrometry provided invaluable insights into the molecular diversity of the petroporphyrin composition and structure. ${ }^{1,4,5,18,19}$ In parallel, other analytical methods, such as nuclear magnetic resonance $(\mathrm{NMR})$ spectroscopy ${ }^{20}$, crystallography ${ }^{21}$, and, more recently, direct molecular imaging with atomic force microscopy molecular imaging, ${ }^{22}$ afforded valuable insights into the structures of purified samples. A recent article introduced the phrase "metallopetroleomics" and provides a comprehensive review of the fractionation 
and characterization of petroleum asphaltenes to study metalloporphyrins. ${ }^{23}$ Additional reviews on methods for studying petroleum porphyrins, ${ }^{24}$ mass spectrometry of geoporphyrins ${ }^{25}$, petroleum analysis ${ }^{26}$, environmental organic matter, ${ }^{27}$ porphyrins in coal, ${ }^{28}$ and porphyrins in heavy oil ${ }^{29}$ are also available. Therefore, we will highlight separation techniques in addition to advances in porphyrin research facilitated by chemical information provided by mass spectrometric techniques and highlight specific advances in ultrahigh resolution FT-ICR mass analyzers, but do not intend this description to be comprehensive for all analytical techniques applied in petroporphyrin characterization.

In 2001, electrospray ionization coupled to Fourier transform ion cyclotron resonance mass spectrometry (FTICR MS) first identified petroporphyrins at the molecular formula level and provided elemental composition assignments for identified vanadyl porphyrins. ${ }^{30}$ Advances in high-resolution mass analyzers have provided new discoveries in studies of petroporphyrin compounds, including the molecular-level characterization of vanadyl, nickel, iron, and gallium porphyrins in petroleum, shale oil, biofuels and natural petroleum seeps. ${ }^{22}$, $31-42$

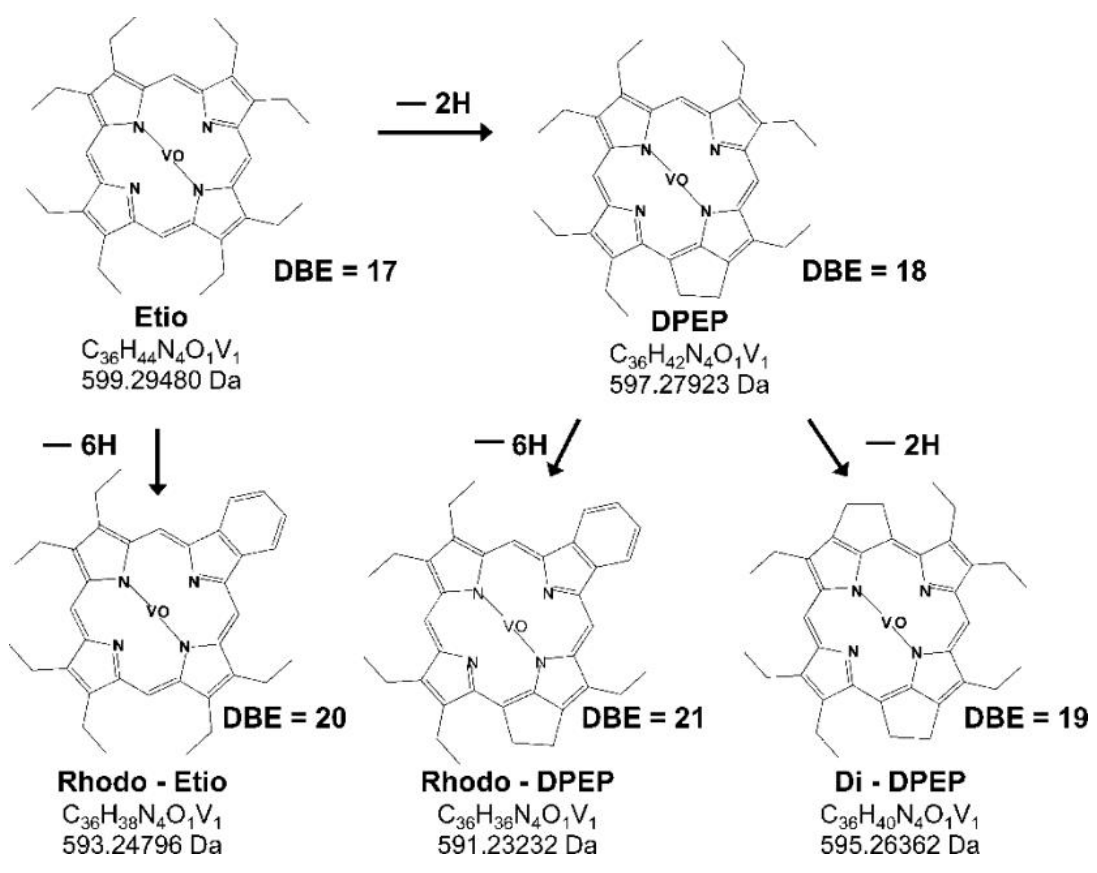

Figure 2. Proposed structures of petroporphyrins according to their number of unsaturated bonds $(D B E=c$ $-h / 2+n / 2+1)$ calculated from their molecular formula based on accurate mass measurements. ${ }^{30,31}$ Reproduced from McKenna, A. M.; Purcell, J. M.; Rodgers, R. P.; Marshall, A. G., Identification of vanadyl porphyrins in a heavy crude oil and raw asphaltene by atmospheric pressure photoionization Fourier transform ion cyclotron resonance (FT-ICR) mass spectrometry. Energy Fuels 2009, 23, (4), 2122-2128. Copyright 2009 American Chemical Society.

\section{- Elucidation of Petroporphyrin Structures}

Collisional Cross Section. Although mass spectrometry provides information on molecular formulas that is used to propose core structures based on general porphyrin tetrapyrrolic macrocycles (Figure 2), it does not differentiate structural isomers. One method that provides separation of structural isomers based on collisional cross sections is ion mobility mass spectrometry (IMS). ${ }^{7,}{ }^{43}$ IMS is a gas-phase separation technique that 
separates ions by molecular size and shape and determines the ion collision cross section (CCS) based on drift time, an intrinsic property of the ion. The CCS of an ion is predicted based on tridimensional structures obtained from molecular modeling. ${ }^{44}$ Due to timing incompatibilities, only a few IMS techniques can be associated with FT-ICR MS detection. ${ }^{45}$ In particular, high-field asymmetric-waveform ion-mobility spectrometry (FAIMS) and trapped ion mobility spectrometry (TIMS) are IMS techniques for which the IMS separation can be adjusted to the scan speed of the FT-ICR mass analyzer. ${ }^{45-47}$ Compared to FAIMS, TIMS is a low field IMS separation that allows derivation of CCS values from experimental results. ${ }^{48}$ Despite its lower resolving power than FT-ICR mass detectors, time-of-flight MS presents an advantage due to the fast acquisition speed. For example, Zheng et al. ${ }^{23}$ combined positive-ion ESI with TIMS-TOF-MS to investigate petroporphyrin aggregates from porphyrin-enriched crude oil fractions. ${ }^{49}$ TIMS-FT-ICR MS was first applied to the characterization of synthetic geologically relevant metalloporphyrins by Benigni et al., ${ }^{50}$ who report octaethylporphyrin as protonated and cationized forms with $\mathrm{Mn}, \mathrm{Ni}, \mathrm{Zn}, \mathrm{VO}$ and $\mathrm{TiO}_{2}$ based on experimental CCS combined with theoretical DFT calculations. Recently, Maillard et al. applied APPI-TIMS-FT-ICR MS to determine the CCS of vanadyl porphyrins from asphaltenes derived from Athabasca bitumen and observed a linear correlation between the CCS and carbon number at the same DBE. ${ }^{51}$ Thus, for a specific core molecular structure, the extent of alkylation results in a linear change in CCS and can be used to estimate the CCS for putative petroporphyrin cores with no alkyl substituents. Finally, theoretical CCS determinations were conducted based on core structures and extrapolated to alkylated petroporphyrins based on the observed linear correlation between CCS and the degree of alkylation. ${ }^{51}$ Based on DFT theoretical calculations, putative structures with theoretical CCS that correlate to experimental values have been proposed.

Atomic Force Microscopy. Recently, the molecular structure of petroporphyrins was reported through a technique combining ultraviolet-visible spectroscopy, FT-ICR MS and noncontact atomic force microscopy (AFM). ${ }^{22}$ Surprisingly, the authors report evidence of one or a few $\beta$ hydrogens present in low carbon number porphyrins, which support dealkylation under catagenesis. Figure 3 shows constant-height atomic force microscopy images of petroporphyrins (M1, M2, M3, and M4), and all exhibit a very repulsive feature in the center, which prevents the AFM tip from approaching the molecule closely enough to resolve the porphyrin core. In addition, several side groups are observed, with varying degrees of bulkiness. ${ }^{22}$

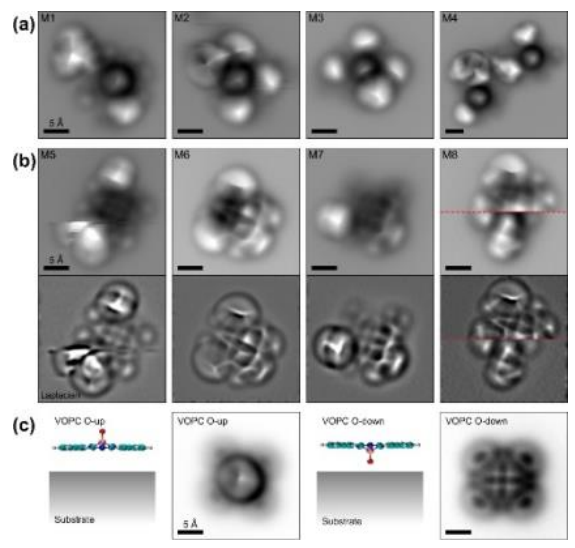

Figure 3. (a) Constant-height AFM images with CO-functionalized tips of petroporphyrins with a strongly repulsive center. (b) Constant-height AFM images with CO-functionalized tips and corresponding Laplace-filtered images of petroporphyrins where atomic resolution of the porphyrin core was achieved. Note that the image of compound M8 is composed of two AFM scans taken at different tip-sample distances, where the scan shown in the lower half was taken at a $1.4 \AA$ larger tip height than the upper 
half. (c) Schematic representation and corresponding AFM images of the two different adsorption positions observed for vanadyl phthalocyanine. Reproduced from Zhao, X.; Xu, C.; Shi, Q., Porphyrins in Heavy Petroleums: A Review. Struct. Bond. 2016, 168, 39-70. Copyright 2016 American Chemical Society.

Tandem Mass Spectrometry. Tandem mass spectrometry has been used for many years to obtain detailed structural information from specifically selected ions. MS/MS involves ion selection using a first mass analyzer, typically a quadrupole analyzer, followed by ion activation by collision or through IR or UV light irradiation. With an FTICR mass analyzer, ultrahigh resolution in-cell ion isolation on the order of a single mass-to-charge ratio is possible and can be fragmented with infrared multiphoton dissociation (IRMPD). ${ }^{52}$ In 1986 and 1989, the Yost group used tandem mass spectrometry with electron ionization to determine the extent of alkylation of geoporphyrins obtained after TLC fractionation. ${ }^{53}$, 54 Beato et al. ${ }^{55}$ used tandem mass spectrometry to characterize geoporphyrins from bitumen and kerogen, showing that the peripheral substituents of $\mathrm{Ni}(\mathrm{II})$ and $\mathrm{VO}$ (II) porphyrins with the same carbon number are similar. ${ }^{55}$ As shown in the study by Laycock et al., ${ }^{56}$ the $(\mathrm{M}-43)+,(\mathrm{M}-44)+$ and $(\mathrm{M}-45)+$ product ions are particularly useful for distinguishing the skeletal type of cycloalkanoporphyrin. Berkel, Glish and McLuckey used MS/MS with $\mathrm{NH}_{3}$ chemical ionization to characterize geoporphyrins. ${ }^{57}$ In 1999, Rosell-Melé et al. ${ }^{58}$ used liquid chromatographytandem mass spectrometry to measure porphyrins from oil shales after a demetallation step. The incorporation of online chromatographic separation limited challenging isobaric interferences. Woltering et al. ${ }^{59}$ recently applied LC-MS ${ }^{\mathrm{n}}$ with a hybrid ion trap-Orbitrap instrument to characterize $\mathrm{Ni}, \mathrm{VO}, \mathrm{Cu}, \mathrm{Zn}$ and $\mathrm{Mn}$ geoporphyrins and, combined with multistage mass spectrometry, accurately identified $>\mathrm{C}_{33}$ porphyrin structures with extended alkyl sidechains. ${ }^{59}$

\section{Methods for the Extraction and Purification of Metalloporphyrins}

In general, the strategies for separating vanadyl porphyrins comprise solvent extraction (e.g., liquid/liquid and extrography), chromatographic methods (e.g., selective affinity HPLC, thin layer chromatography, and silica gel column chromatography), supercritical fluid extraction, and novel/prospective methods such as molecular imprinted polymers. We will categorize these methods and highlight noteworthy contributions that have advanced the mass spectral detection of porphyrins below.

\section{— Solvent Extraction: Solid/Liquid Extraction, Liquid/Liquid Extraction and Extrography}

$\mathrm{Xu}$ et al. ${ }^{60}$ first isolated vanadyl and nickel porphyrins from two Chinese heavy crudes that were purified by silica gel chromatography, demetallized with methyl sulfonic acid, and analyzed using LDI TOFMS. Here, extrography isolated crude oil fractions enriched in vanadyl porphyrins (methanol extraction) and nickel porphyrins (acetonitrile extraction) based on adsorption on diatomite followed by Soxhlet extraction,

and compounds were subsequently purified with an eluotropic gradient of cyclohexane/dichloromethane/chloroform. ${ }^{60}$ LDI TOF-MS identified etioporphyrins with a carbon number ranging from $\mathrm{C}_{26}-\mathrm{C}_{40}$ in fractions of purified $\mathrm{VO}$ and $\mathrm{Ni}$ porphyrins. Liu et al. ${ }^{61}$ further extended porphyrin characterization with silica gel chromatography fractions of Chinese heavy oil and simultaneously detected vanadyl porphyrins, sulfur-containing vanadyl porphyrins, oxygen-containing vanadyl porphyrins and nickel porphyrins using positive-ion ESI FT-ICR MS, and surprisingly detected nickel porphyrins as radical cations $\left(\mathrm{M}^{+\bullet}\right)$. The authors attributed stable radical cation formation in positive-ion ESI (as previously observed by Rodgers et $\mathrm{al}^{30}$ ) to the low oxidation potential of nickel porphyrins. Another study sequentially fractionated Venezuelan Orinoco heavy crude by extrography and silica gel column chromatography into subfractions that were characterized by ESI FT-ICR MS and identified three new types of vanadyl porphyrins corresponding to $\mathrm{C}_{n} \mathrm{H}_{m} \mathrm{~N}_{4} \mathrm{VO}_{2}, \mathrm{C}_{n} \mathrm{H}_{m} \mathrm{~N}_{4} \mathrm{VO}_{3}$, and $\mathrm{C}_{n} \mathrm{H}_{m} \mathrm{~N}_{4} \mathrm{VO}_{4} .{ }^{36}$ Based on aromaticity calculated as double bond equivalents 
(DBE $=$ number of rings plus double bonds to carbon, $\mathrm{DBE}=C-h / 2+n / 2+1$, calculated from elemental composition $\left.\mathrm{C}_{c} \mathrm{H}_{h} \mathrm{~N}_{n} \mathrm{O}_{o} \mathrm{~S}_{s}\right)^{62}$, the authors report oxygen incorporation into porphyrin core structures as ketone/aldehyde and carboxylic acid moieties. ${ }^{36}$

Liu et al. ${ }^{61}$ reported the isolation of vanadium compounds by extrography and silica gel open column chromatography with methanol, dimethylformamide, and toluene for hydrotreated products that were further separated into subfractions through silica gel chromatography and an elutropic gradient comprised of cyclohexane, dichloromethane, and methanol. Positive-ion ESI FT-ICR MS identified vanadium compounds in toluene extracts as the most resistant to hydrotreatment, and the vanadium compounds in the methanol extract, primarily $\mathrm{C}_{n} \mathrm{H}_{m} \mathrm{~N}_{4} \mathrm{~V}_{1} \mathrm{O}_{1}$, were removed through hydrotreatment due to side chain cracking. ${ }^{63}$ Chauhan et al. ${ }^{64}$ reported the extraction of vanadium and nickel from diluted oil sand bitumen with hydrochloricacidified, aqueous sodium chloride, and water-diluted ionic liquids, investigated the dissociation equilibria differences and partitioning of vanadium and nickel extraction, and suggested improved extraction of nickel porphyrins with $\mathrm{HCl}$ acidification, dilution with aqueous $\mathrm{NaCl}$ and dilution with water. Gascon et al ${ }^{65}$. were the first to report the gel permeation chromatography (GPC) separation of vanadium and nickel species found in maltenes. Here, maltenes were extracted with methanol, acetonitrile and dimethylformamide and subsequently separated by GPC with tetrahydrofuran as the mobile phase, which separates petroleum fractions into high molecular weight (HMW), medium molecular weight (MMW), and low molecular weight (LMW) fractions. The authors hypothesize that the final fraction is enriched in disaggregated/free molecules whereas the HMW fraction consists of highly aggregated species, and conclude that liquid-liquid extraction of maltenes with acetonitrile selectively removed low molecular weight vanadium compounds, whereas dimethylformamide extracted low and medium-molecular weight species from the high molecular weight species that remained in the maltene remnant. ${ }^{65}$ Notably, the authors documented the separation of three distinct fractions of vanadium and nickel compounds in maltenes based on molecular weight and aggregation tendency determined using GPC. ${ }^{13}$ The same authors performed a similar study by directly applying the technique to asphaltene using successive extraction with dimethylformamide, acetone and finally acetonitrile. Again, two highly aggregated enriched porphyrin fractions were hypothesized in the DMF and acetone fractions based on GPC. Some disaggregated/free porphyrins were detected in the last ACN fraction. These methanol and ACN extracts of maltene and asphaltene correspond to $45 \%$ and 5\%, respectively, of the total V compounds, indicating that most of the $\mathrm{V}$-porphyrins are in an aggregated form in crude oil samples.

\section{- Supercritical Fluid Extraction and Fractionation (SFEF)}

Supercritical fluid extraction separates heavy oil into fractions, which are then further characterized for porphyrins. Supercritical fluid extraction applied to vacuum residues derived from an extraheavy crude oil (Venezuelan Orinoco) separates residue species based on molecular weight and degree of molecular condensation. ${ }^{66}$ The authors identified a series of compounds with the most abundant peak at $m / z \sim 530$ detected using + APPI FT-ICR MS in the SFEF end-cut, which also contained $\sim 70 \mathrm{wt} \% \mathrm{C}_{7}$ asphaltenes. These compounds corresponded to vanadyl porphyrins with DBE values ranging from 17-21.

\section{- Chromatographic Fractionation of Metalloporphyrins}

Chromatographic separation and purification methods applied to petroporphyrins are described in detail below.

Selective affinity chromatography. A portion of the metalloporphyrin fraction isolated from asphaltenes through reactive modification and affinity chromatography through derivatization of vanadyl porphyrin targets was reported by Yin et al. ${ }^{67}$ This method modifies vanadyl porphyrin complexes through a reaction with oxalyl chloride followed by long-chain alkylamine or perfluoroalkyl-amiline to yield an imdio vanadium derivative 
containing octadecyl or perfluorooctyl side chains. Derivatized vanadium-containing porphyrins were selectively isolated by affinity column chromatography with $\mathrm{C}_{18}$-silica gel or perfluorous $\left(-\mathrm{C}_{8} \mathrm{~F}_{17}\right)$ silica gel. The authors report the removal of tagged metalloporphyrins from petroleum asphaltenes, with a mass recovery of $\sim 15-40 \%$ of the total vanadium and nickel content with minimal asphaltene loss. ${ }^{68}$

Size-exclusion chromatography/gel permeation chromatography. Acevedo et al. ${ }^{69}$ described a microsized exclusion chromatography system coupled to a mass spectrometer with an inductively coupled plasma ion source ( $\mu$ SEC-HR ICP MS, or $\mu$ SEC ICP) to analyze metals in four asphaltene fractions. Trapped petroporphyrins were characterized from three fractions derived from three separate asphaltene samples of Boscan, Cerro Negro and Furrial crudes: A1 (toluene insoluble), A2 (toluene soluble), and TC (trapped compounds). ${ }^{69}$ Nickel porphyrins were distributed in approximately all types of asphaltene aggregates (toluene insoluble, toluene soluble and heptane-soluble fractions), and overlapping SEC chromatograms were reported with sulfur for all vanadium and nickel profiles at retention times below the exclusion limit, indicating that metalloporphyrins are interlocked with asphaltene species and form aggregates in solution, consistent with previous simulations. ${ }^{12,69,70}$

Gel permeation chromatography. Desprez et al. ${ }^{71}$ first studied trends of correlations between sulfur fraction retention times, distillation cut temperature with a boiling point less than $560{ }^{\circ} \mathrm{C}$, viscosity, and the proportion of trapped sulfur-containing compounds using gel permeation chromatography (GPC) with inductively coupled plasma high resolution mass spectrometry (ICP HR MS). Sulfur, vanadium and nickel compounds from four crude oils, residues and SARA fractions were further determined based on GCP ICP HR MS and revealed trimodal distributions in crude oils, resins and residues. ${ }^{71}$ Interestingly, asphaltenes were enriched in highly aggregated Ni-/V-containing compounds (HMW fraction), whereas resins contained greater amounts of MMW and LMW species. ${ }^{72}$ An analysis of gel permeation chromatography (GPC) fractions from an asphaltene sample using direct-infusion FT-ICR MS highlights an inverse correlation of the asphaltene aggregate size and aromaticity, but the analysis was limited due to the low ionization efficiency of larger, aliphatic compounds. ${ }^{73}$ In other words, the compositional range (DBE and carbon number) of HMW species revealed abundant species with a $\mathrm{DBE}<20$ and up to $\mathrm{C}_{50}$. Conversely, the LMW/disaggregated material contained a high relative abundance of molecules with a DBE $>15$ and aromaticity near the polycyclic aromatic hydrocarbon planar limit. ${ }^{74}$ GPC separation with online detection by positive-ion APPI FT-ICR MS highlights the presence of highly abundant, aliphatic asphaltene aggregates. Furthermore, the authors report that the composition of vanadyl porphyrins eluting in the most aggregated region spans the largest carbon number range, and as aggregation decreases, the carbon number range narrows and the average $\mathrm{H} / \mathrm{C}$ ratio decreases to approximately 1.0 , corresponding to porphyrin species with minimal alkyl chain pendant groups. ${ }^{75}$ Additional studies have highlighted the effect of GPC on porphyrin characterization in heavy oil ${ }^{69,71-73,75-80}$ and applied GPC to understand hydrodemetallization and hydrodesulfurization processes. ${ }^{81}$

High-performance thin-layer chromatography. Moulian et al. ${ }^{82}$ studied the contribution of porphyrins to asphaltene aggregation and reported an increase in the molecular weight of asphaltene aggregates in the presence of metalloporphyrins that interacted with asphaltene aggregate surfaces, and these species likely play a critical role in asphaltene aggregation, coprecipitation, and demetallation processes. Importantly, this study directly implicates porphyrins in the stabilization of noncovalent asphaltene aggregates, consistent with simulations reported more than a decade previously. ${ }^{12,83}$ Additionally, the authors studied porphyrins from asphaltene fractions enriched in single-core/island motifs (acetone extrography fraction) and multicore/archipelago structures (Tol/THF/MeOH extrography fraction), obtained using methods reported elsewhere. ${ }^{84-86}$ The authors separated porphyrins from the extrography fractions through thin-layer chromatography using cellulose as the stationary phase and $\mathrm{DCM} / \mathrm{MeOH}$ as the eluent, which yielded a 
continuous elution profile with two prominent TLC fractions: noneluted (highly polar) and eluted. Characterization by laser ablation inductively coupled plasma mass spectrometry revealed the existence of abundant V-containing compounds in the TLC subfractions from the asphaltene extrography fractions. In particular, the acetone fraction contained abundant $\mathrm{V}$-containing compounds in the eluted fraction, whereas $\mathrm{Tol} / \mathrm{THF} / \mathrm{MeOH}$ was enriched in noneluted species. However, molecule-level characterization using MALDI FT-ICR MS revealed vanadyl porphyrins for only the TLC fraction eluted with acetone. ${ }^{82}$ The combination of molecule-level (FT-ICR MS) and elemental analyses (ICP-MS) proved that abundant porphyrins are inaccessible to FT-ICR MS because of matrix effects and ionization efficiencies. ${ }^{82}$ Importantly, these porphyrins are present in asphaltene fractions that contain abundant archipelago asphaltenes, which experience a disproportional aggregation tendency compared with island structural motifs. Furthermore, Moulian et al. ${ }^{82}$ present a method to separate free porphyrins from asphaltenes based on high-performance thin-layer chromatography (HPTLC).

Ramírez-Pradilla et al. ${ }^{13}$ reported the liquid-liquid extraction of crude oil with acetonitrile and obtained fractions enriched in vanadium and nickel, followed by purification with high-performance thin-layer chromatography fractionation (HPTLC, aminopropyl-bonded silica) using DCM as the eluent. ${ }^{13}$ The authors applied a novel MALDI matrix that favors electron-transfer reactions ${ }^{87,88}$ coupled to molecule-level FT-ICR MS and simultaneously detected 518 molecular formulae (the highest number of $\mathrm{Ni}$, VO, oxygenated and sulfur-containing porphyrins detected to date) in a single crude oil sample with MALDI FT-ICR MS. Interestingly, S-containing vanadyl porphyrins contain 6 more DBEs than porphyrins without sulfur, consistent with earlier reports. ${ }^{31}$

Microwave irradiation. Several studies indicate the agreement in the literature that a fraction of vanadium is locked into asphaltene aggregates and remains inaccessible to many techniques, including UV-Vis spectroscopy. ${ }^{89,} 90$ One method proposes the separation of porphyrins from asphaltene aggregates from Canadian oil sand bitumen using polar solvent mixtures (e.g., methanol/toluene) and microwave irradiation, ${ }^{91}$ which was previously reported to clean plugged horizontal wellbores and used in demulsification. ${ }^{92,}{ }^{93}$ Fan et al. ${ }^{91}$ report rapid asphaltene separation into soluble and insoluble fractions by microwave irradiation, with the soluble material containing abundant vanadyl porphyrins. After microwave treatment, asphaltene samples exhibit a more prominent Soret band than those without microwave treatment. The authors report limited release of nickel porphyrins compared to vanadyl porphyrins and conclude that the disproportionate selectivity for the release of vanadyl porphyrins is due to the efficient absorption of microwave irradiation by the vanadyl $(\mathrm{V}=\mathrm{O})$ group. The proposed mechanism for vanadyl porphyrin release is based on the formation of asphaltene vesicles in polar solvent mixtures (e.g., toluene/methanol). Previous studies have also implicated porphyrins in asphaltene aggregate stabilization. ${ }^{94,95}$

\section{- Purification of Metalloporphyrins}

Ultrahigh purification of petroporphyrins. Rytting et al. ${ }^{96}$ report a method for producing ultrahigh purity vanadyl porphyrin fractions from heavy crude and bitumen to enable characterization and inclusion into model studies of asphaltene-petroporphyrin intermolecular interactions. Fractions are prepared through Soxhlet extraction to yield a porphyrin-rich fraction that is further purified using three consecutive separation steps based on extrography on silica-packed columns and chromatography on alumina-packed columns (Figure 4). The extensive separation method yields purified porphyrins that can be further purified ( $>85 \%$ petroporphyrins by weight) through temperature and centrifugation to yield soluble fractions and highlights the complexity of the purification process, often requiring several weeks to obtain a few milligrams of purified petroporphyrin material. ${ }^{96}$ Furthermore, purified porphyrins are characterized by small-angle neutron scattering. The collective results suggest a central role in asphaltene aggregation and interfacial film formation dependent on 
the porphyrin structure ${ }^{97}$ and interfacial film formation. ${ }^{98}$ More functionalized porphyrins that contain sulfur and several oxygen atoms promote asphaltene flocculation at low temperatures, as polyfunctionality enables multiple intermolecular interactions with neighboring asphaltene molecules. Both synthetic and extracted highly functionalized porphyrins promote asphaltene flocculation, whereas simpler porphyrins disrupt asphaltene aggregation. ${ }^{97}$

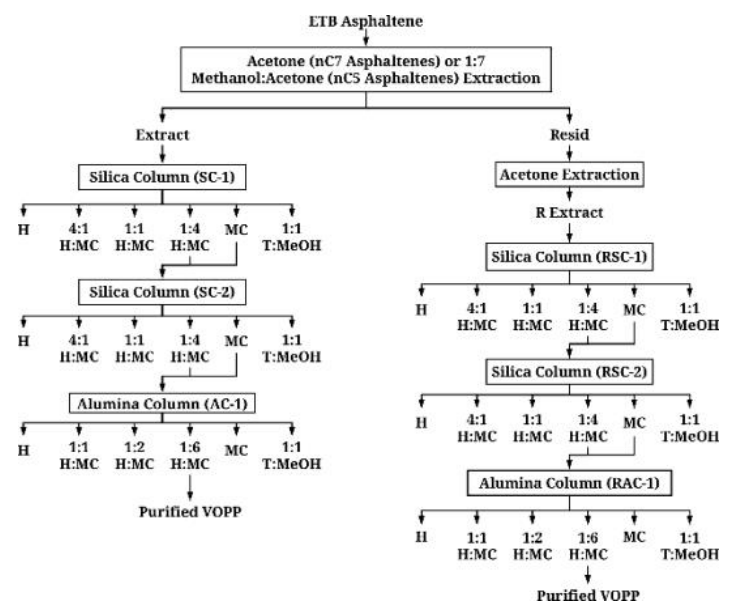

Figure 4. ETB asphaltene VOPP enrichment procedure. Here, ETB is subjected to an extraction step, which produces an extract and a residuum. The extract is further fractionated on a silica column (SC-1) using the series of solvents shown below the silica column, including hexane $(H)$, hexane:methylene chloride mixtures (H:MC), methylene chloride (MC), and toluene:methanol mixtures (T:MeOH). The 1:4 H:MC and $M C$ eluents are combined and further fractionated on an additional silica column (SC-2). Again, the 1:4 H:MC and MC eluents from SC-2 are combined and further fractionated on an alumina column (AC1), where the 1:6 H:MC eluent contains purified VOPPs. The residuum from the original extraction is also further fractionated on several columns, which are named with an $R$ prefix to specify that they are using the residuum from the original extraction. ${ }^{96,} 97$ Reproduced from Rytting, B. M.; Singh, I. D.; Kilpatrick, P. K.; Harper, M. R.; Mennito, A. S.; Zhang, Y., Ultrahigh-purity vanadyl petroporphyrins. Energy Fuels 2018, 32, (5), 5711-5724. Copyright 2018 American Chemical Society.

Sulfocationite isolation. Recent novel separation methods to purify porphyrins from heavy oil have been investigated and show promise for expanding the knowledge of porphyrin compositions. Mironov et al. developed a method for the chromatographic preparation of high-purity vanadyl porphyrins based on a sulfuric acid cation exchanger readily prepared from silica gel and sulfuric acid. ${ }^{99}$ With a silica gel/sulfuric acid/water weight ratio of $60 / 15 / 25$, up to $\sim 50 \%$ of vanadyl porphyrins pass through the column without retention, whereas nonporphyrin impurities are retained on the stationary phase. ${ }^{99}$ Vanadyl porphyrins isolated from asphaltenes derived from a heavy oil from the Volga-Ural basin were purified using a novel strong acid cationexchange resin and asphaltene sulfocationite method. ${ }^{100}$ Subsequent characterization of purified porphyrins by MALDI ToF-MS showed that the composition of isolated vanadyl porphyrins depended on the chemical nature of sulfocationite. Furthermore, purification of asphaltene sulfocationite resulted in a 1.1-1.9-fold increase in non-DPEP vanadyl porphyrin structures. ${ }^{100}$ Application of the sulfocationite porphyrin purification method to resins and asphaltenes from three heavy oils of different origins and vanadium contents combined with MALDI TOF-MS identified DPE, Etio, Di-DPEP, and Rhodo-DPEP vanadyl porphyrins across all samples, with resins and asphaltenes from the same oil exhibiting significant differences in the group composition of purified vanadyl porphyrins. ${ }^{101}$ 


\section{— Ionization Techniques for MS of Metalloporphyrins}

Electron impact ionization of metalloporphyrins. Electron impact ionization, a hard ionization method, is not suitable for the analysis of vanadyl and nickel porphyrins due to the low volatility of these species and the high internal energy after ionization, which results in the fragmentation of pendant side groups. Nevertheless, the tetrapyrrole core is stable (not fragmented) even when ionized with high-energy electrons $(70 \mathrm{eV})$, as revealed by native vanadyl/nickel porphyrins and their demetallized forms. An early study by Grigsby and Green reported the characterization of a vanadium-enriched fraction from the $>700{ }^{\circ} \mathrm{C}$ residue of Cerro Negro heavy oil with low-eV HRMS. ${ }^{102}$ The V-enriched fraction was obtained using liquid chromatography and shown to contain $19500 \mathrm{ppm}$ vanadium. Low-eV HRMS was assisted by sample introduction via probe microdistillation, as it enables the characterization of aromatic and polarizable species in low-volatility mixtures. Mass spectrometry analysis of the generated ions was performed with a high-resolution TOF instrument. The authors concluded that the most abundant V-containing compounds were etioporphyrins with molecular weights ranging from $\mathrm{m} / \mathrm{z} 487$ and 879 . The presence of porphyrins with cyclo-alkyl/aromatic pendant groups and a hydrogen deficiency, or $Z$ numbers between -32 and $-50(Z=-2$ (DBE) $+n+2$ in which $n$ is the number of nitrogen atoms), was also observed. ${ }^{102,103}$

Soft ionization methods such as ESI, APCI, and APPI have produced promising results for the intact ionization of nickel/vanadyl porphyrins. However, APCI still suffers some degree of fragmentation, which is presumed to result from the collision of molecules at atmospheric pressure. ${ }^{104,105}$

Electrospray ionization (ESI) of metalloporphyrins. Rodgers et al. ${ }^{30}$ first applied positive ion ESI FT-ICR MS to identify metalloporphyrins in a Venezuelan heavy oil (Cerro Negro) isolated via column chromatography. The authors observed a predominance of the dimeric forms of vanadyl and nickel porphyrins, which were dissociated with minimal covalent bond fragmentation, using infrared multiphoton dissociation (IRMPD). ${ }^{30}$ Ionization conditions (concentration, solvents, and ESI needle voltage), ion transfer from the source to the ICR cell, and FT-ICR MS excitation/detection were optimized in subsequent studies. Thus, the prevalence of porphyrin dimers was not noted in further studies.

Electrochemical oxidation in ESI FT-ICR MS improved the detection of nickel and vanadyl porphyrins in porphyrin-enriched residue fractions and identified nickel porphyrins. ${ }^{34}$ Chen et al. ${ }^{106}$ developed a method to enhance the response of nickel porphyrins in ESI by introducing an electrochemical oxidation reaction. Under optimized conditions, nickel and vanadyl porphyrins are directly ionized as molecular radical cations $\left([\mathrm{M}]^{+*}\right)$ via electrochemical oxidation due to their low oxidation potential and gas-phase ionization energy. ${ }^{106}$ This method is capable of directly analyzing both nickel and vanadyl porphyrins in a vacuum residue without any prior sample preparation. ${ }^{106}$

Atmospheric pressure photoionization (APPI) of metalloporphyrins. Because APPI ionizes both polar and nonpolar compounds (e.g., hydrocarbons and porphyrins) in the gas phase simultaneously and produces both radical ions and protonated/deprotonated ions; the resulting mass spectrum is more complex, with up to five times the number of peaks compared to electrospray ionization. The number of mass spectral peaks detected increases in a more complex mass spectrum. ${ }^{107,} 108$ APPI was first coupled to FT-ICR MS for heavy oil characterization and first characterized the nonpolar species in samples from South America in 2006-2007 107 111. Vanadyl porphyrins and sulfur-containing vanadyl porphyrins were first identified in a fractionation asphaltene sample, and a concurrent increase in DBE and carbon number may occur through benzene and naphthene addition as exocyclic pendant groups in the porphyrin ring structures. ${ }^{112}$ Qian et al. ${ }^{38}$ further reported a wide diversity of petroporphyrin structures that contain multiple sulfur and oxygen atoms $\left(\mathrm{C}_{c} \mathrm{H}_{2 c+2} \mathrm{~N}_{4} \mathrm{VO}_{o} \mathrm{~S}_{s}\right)$ 
in vacuum residue using APPI FT-ICR MS. ${ }^{38}$ The first comprehensive characterization of vanadyl porphyrins in unfractionated heavy petroleum and virgin asphaltenes using APPI FT-ICR MS was performed by McKenna et al. ${ }^{31}$ The authors highlight the need for FT-ICR MS to achieve unambiguous molecular formula assignment $(<300 \mathrm{ppb})$ and document the likelihood of misassigning vanadyl porphyrin peaks $\left(\mathrm{N}_{4} \mathrm{O}_{1}{ }^{51} \mathrm{~V} 1 \mathrm{class}\right)$ as high DBE $\mathrm{O}_{2}$ compounds. Vanadyl porphyrins were detected as radical cations $\mathrm{M}^{+\bullet}$ and protonated molecules $[\mathrm{M}+\mathrm{H}]^{+}$. Trends in the abundance of specific homologous series accounted for the structural diversity of vanadyl porphyrins in heavy crudes and asphaltenes. For example, the identified alkyl-substituted $\mathrm{N}_{4} \mathrm{O}_{1} \mathrm{~V}_{1}$ species in Athabasca bitumen asphaltenes revealed DBE values ranging from 16, which corresponds to the tetrapyrrole core, to 23 , which suggests the presence of several naphthenic rings or aromatic moieties as side groups. $^{31}$

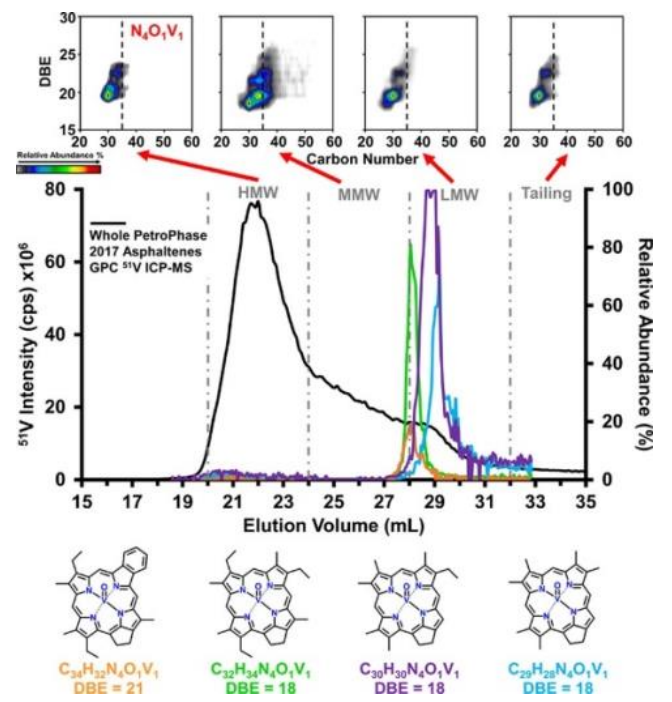

Figure 5. DBE vs. carbon number plots for the $\mathrm{N}_{4} \mathrm{O}_{1}{ }^{51} \mathrm{~V}_{1}$ class in the various $\mathrm{GPC}$ regions from whole PetroPhase 2017 asphaltenes (upper panel) and relative abundance as a function of elution volume of the most abundant $\mathrm{N}_{4} \mathrm{O}_{1}^{51} V_{1}$ formulas (middle panel). Data were derived from (+) APPI 21 T FT-ICR MS characterization. The GPC ${ }^{51} V$ ICP-MS chromatogram (black) is included as a reference, and the most likely molecular structures of the most abundant vanadyl porphyrins are presented in the lower panel. Reproduced from Chacón-Patiño, M. L.; Moulian, R.; Barrère-Mangote, C.; Putman, J. C.; Weisbrod, C. R.; Blakney, G. T.; Bouyssiere, B.; Rodgers, R. P.; Giusti, P., Compositional Trends for Total Vanadium Content and Vanadyl Porphyrins in Gel Permeation Chromatography Fractions Reveal Correlations between Asphaltene Aggregation and Ion Production Efficiency in Atmospheric Pressure Photoionization. Energy Fuels 2020, 34, (12), 16158-16172. Copyright 2020 American Chemical Society.

Vanadyl porphyrins have been detected in asphaltenes isolated from vacuum gas oil distillate cuts and in pentane, in-between $\mathrm{C}_{5} \mathrm{C}_{7}$ asphaltenes, and heptane asphaltenes using APPI FT-ICR MS. ${ }^{113,114}$ Additional studies have applied APPI FT-ICR MS to asphaltene extrography fractions and highlight structural characterization using infrared multiphoton dissociation (IRMPD), confirming the dominance of single core vanadyl porphyrin structures. ${ }^{84}$ Supercritical fluid extraction and fractionation (SFEF) of Venezuelan Orinoco extra heavy crude vacuum residue concentrates vanadyl porphyrins in high boiling end cuts detected using APPI FT-ICR MS. ${ }^{66}$ Furthermore, Chacón-Patiño et al. ${ }^{15}$ investigated the molecular composition of vanadyl porphyrins in PetroPhase 2017 asphaltenes and extrography fractions, with a specific focus on the molecular composition of vanadyl porphyrins as a function of the aggregate size distribution, using GPC ICP-MS and online GPC APPI FT-ICR MS at 21 tesla (Figure 5). The authors performed quantitative detection of vanadium using GPC ICP-MS and concluded that the majority of the vanadyl porphyrin ions are produced 
from later eluting GPC fractions (low aggregation LMW part) and that highly aggregated fractions contain abundant porphyrins with much longer homologous series than those species from the less aggregated GPC fractions.
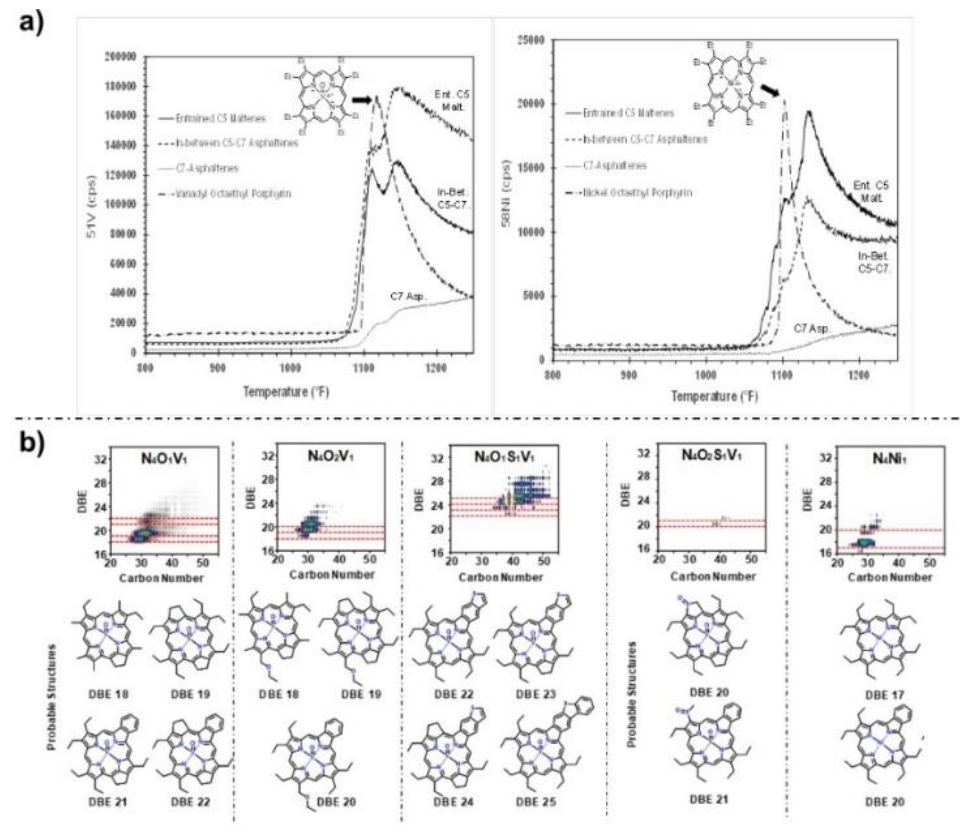

Figure 6. a). Trace of the vanadium and nickel signals versus boiling temperature $\left({ }^{\circ} \mathrm{F}\right)$ for the entrained $C 5$ maltenes, in-between C5-C7 asphaltenes, C7 asphaltenes in a Venezuelan heavy oil. b). Isoabundancecontoured plots of DBE vs. carbon numbers and probable structures of the vanadium/nickel-containing species for the in-Between C5-C7 asphaltenes. ${ }^{114}$ Reproduced from Chacón-Patiño, M. L.; Nelson, J.; Rogel, E.; Hench, K.; Poirier, L.; Lopez-Linares, F.; Ovalles, C., Vanadium and nickel distributions in Pentane, In-between C5-C7 Asphaltenes, and heptane asphaltenes of heavy crude oils. Fuel 2021, 292, 120259. Copyright 2021 American Chemical Society.

Porphyrins from $\mathrm{C}_{5}-\mathrm{C}_{7}$ asphaltenes isolated from Venezuelan heavy oils and a NIST vanadium crude oil standard show a multimodal distribution for the boiling point ranges of vanadium-containing compounds (Figure 6a). ${ }^{114}$ Positive ion APPI FT-ICR MS revealed that the molecular composition of vanadyl and nickel porphyrins is multimodal in terms of aromaticity (DBE). For example, the $\mathrm{N}_{4} \mathrm{O}_{1} \mathrm{~V}_{1}$ and $\mathrm{N}_{4} \mathrm{O}_{2} \mathrm{~V}_{1}$ classes comprised dominant homologous series with a DBE $<22$. However, when sulfur was present, e.g., in the $\mathrm{N}_{4} \mathrm{O}_{1} \mathrm{~S}_{1} \mathrm{~V}_{1}$ class, the composition shifted toward a higher DBE (increase of 4-6 units, Figure 6b). Similarly, nickel porphyrins correspond to two main homologous series and indicate a bimodal molecular structure (Figure 6b), which implicates this chemical characteristic in multimodal distributions of boiling point detected using high temperature gas chromatography (GC) coupled with ICP-MS.

Laser desorption ionization (LDI) of metalloporphyrins. The application of laser desorption ionization (LDI) to heavy oil and asphaltenes enriched in metalloporphyrins has been controversial due to the prevalence of noncovalent cluster formation in the desorption plume for complex samples that result in aggregate formation. ${ }^{60,116}$ Cho et al. ${ }^{117}$ evaluated laser desorption ionization for vanadyl and nickel porphyrins and reported five types of $\mathrm{VO}^{2+}$ and $\mathrm{Ni}^{2+}$ porphyrin complexes (etio, DPEP, rhodo-etio, rhodo-DPEP, and diDPEP) observed with LDI compared to only three porphyrin complexes observed with +APPI, but reported the fragmentation of porphyrins due to loss of $\mathrm{CH}_{3}$ induced by LDI. Interestingly, Kachadourian et al. ${ }^{118}$ found that the number of $\mathrm{N}$-ethyl losses for a series of $\beta$-substituted cationic metalloporphyrins depends on the redox 
state of the metal. The authors suggested fragmentation in LDI as a method to determine the metal oxidation state in metalloporphyrins. ${ }^{118} \mathrm{Xu}$ et al. combined UV-Vis and LDI TOF MS to discriminate vanadyl porphyrins in two Chinese crude oil samples. A Soret band $(406 \mathrm{~nm})$ in the UV-Vis spectra of some extracts and a MWD ranging from m/z 430 to 580 confirmed the presence of petroporphyrins. The thermal maturity of the crude oil samples was determined by calculating the $\Sigma$ DPEP/ $/$ ETIO ratio. ${ }^{60}$ Likewise, porphyrins isolated from a heavy oil residue $\left(500^{+}{ }^{\circ} \mathrm{C}\right)$ of Chinese Gudao heavy crude were characterized using LDI TOF-MS, and nickel porphyrin etio homologs from $\mathrm{C}_{25}-\mathrm{C}_{34+}$ were reported. Based on the $\Sigma \mathrm{DPEP} / \Sigma E T I O$ ratio of $\sim 1.04$, Gudao oil is nearing maturity. ${ }^{119}$

Matrix-assisted laser desorption ionization (MALDI) of metalloporphyrins. Alternative charging pathways in MALDI can increase the detection of petroporphyrins present at lower concentrations compared to infusion ionization techniques (e.g., electrospray ionization and atmospheric pressure photoionization). Secondary electron transfer (ET) reactions in MALDI involve charge transfer between the matrix primary ions (radical cations) and neutral analytes. Thus, the relative ionization energies (IEs) of the species involved determine the spontaneity of the reaction. ET is thermodynamically favored when the IE of the matrix is higher than the IE of the analyte (IEM>IEA). ${ }^{120}$ The molecular complexity of crude oil results in a broad range of IE values for its components, extending from 6.5 to $12 \mathrm{eV}$. Interestingly, petroporphyrins exhibit some of the lowest IE values in crude oils due to their highly conjugated, heteroatom-containing aromatic tetrapyrrole core. ${ }^{70}$ Therefore, selective ionization by ET reactions is possible by selecting a matrix with an IE greater than that of the petroporphyrin homologous series while suppressing the ionization of molecules with a higher IE than the matrix in the crude oil sample. ${ }^{121}$

Giraldo-Dávila et al. ${ }^{122}$ were the first to illustrate the selectivity of the ET approach in the analysis of two South American crude oils. The authors showed that petroporphyrins (IE 6.5 to $7.0 \mathrm{eV}$ ) were selectively ionized as radical cations in a MALDI-TOF instrument using a cyanophenylenevinylene derivative with an IE of $8.2 \mathrm{eV}$ for the matrix. ${ }^{122}$ Subsequently, using the ET MALDI approach with an FT-ICR instrument, Ramírez-Pradilla et al. ${ }^{13,121}$ reported the highest number of $\mathrm{Ni}-$, VO-, oxygenated and sulfur-containing porphyrins in a single crude oil sample (868 species) through liquid-liquid extraction and high-performance thin-layer chromatography fractionation. Petroporphyrins have a low ionization energy (between 6.5 and 7.0 $\mathrm{eV}$ ), and thus, when combined with high ionization energy matrices, more than 500 different petroporphyrins can be identified since electron-transfer reactions are favored. ${ }^{122}$ In contrast to APPI and LDI, the ET MALDI approach not only favors selective petroporphyrin detection but also decreases spectral complexity, increasing analytical figures of merit such as the S/N ratio and mass accuracy. These effects facilitate the development of ancillary identification strategies for petroporphyrins, such as isotopic fine structure analysis and data refinement with Kendrick mass defect (KMD) plots. ${ }^{123}$

\section{- Molecular Simulations and Computational Approaches}

Porphyrins are organometallic complexes that have been extensively investigated using computational approaches since the early 1990 s to obtain knowledge of their structures ${ }^{124}{ }^{125}$, electronic properties ${ }^{126}$ and reactivity ${ }^{127}$. As previously discussed, petroleum metalloporphyrins are primarily vanadyl porphyrins and nickel porphyrins. In this section, we describe the methodologies implemented to investigate these porphyrins, the results obtained from these studies and the links with experimental techniques.

\section{- Computational Approaches for Metalloporphyrins}


First, we describe the methodology needed to investigate metalloporphyrins using computational approaches, and we try to highlight the key features of these systems and their consequences in the choice of a methodology. Theoretical chemistry methodologies are mainly split into two families, namely, quantum chemistry calculations and molecular mechanics calculations. Both aim to provide the energy of molecular systems using approximations or empirical laws.

Quantum chemistry calculations are based on the resolution of the Schrödinger equation and provide the electronic states of the systems characterized by wavefunctions and energy. These methodologies provide a full description of the system by considering explicitly the electronic density, which opens various fields of investigation, including electronic or optical transitions, electronic transfer, chemical bond analysis and chemical reactivity. However, the limitation of the accuracy of these methodologies is that they are computationally costly. Depending on the required accuracy, they are thus limited to at most a few hundred atoms in high-performance computing centers. Calculations mainly consist of the implementation of density functional theory (DFT) calculations.

On the other hand, molecular mechanics aims to provide empirical laws, usually analytical expressions, allowing the computation of the energy and forces of a large system with a high efficiency. These laws are called force fields and are usually parametrized against experimental data or quantum chemistry calculations. The efficiency of these calculations enables the implementation of molecular dynamics simulations along which the trajectory of large or complex systems is integrated over time. Currently, simulations of hundreds of thousands of atoms are considered. However, in these approaches, electrons are usually not described explicitly but are represented in terms of partial charges, dipoles or even neglected in some hydrocarbon systems without any heteroatoms.

\section{- Molecular Mechanics Methodologies Applied to Metalloporphyrins}

From the perspective of theoretical chemistry, metalloporphyrins and, in particular, petroleum metalloporphyrins (petroporphyrins) are complex systems for several reasons. First, considering the structure, the nucleus of the porphyrin with its four pyrrole rings already contains approximately 40 atoms. This structure may explain why the first studies of nickel porphyrins implemented molecular mechanics methodologies in 1991. ${ }^{128}$ This work focused on nickel porphyrins as cofactors of reductase enzymes in methanogenic bacteria. Moreover, when considering petroleum porphyrins, the structures of the compounds have not yet been completely elucidated, particularly the length and composition of lateral chains crafted on the nucleus. That point is also a bottleneck for computational approaches for which the structure of the system is a starting point, and considering an excessively large chemical diversity involves a very large computational effort. The next point of complexity concerns the binding of the metal and the porphyrin. The mixture of organic and inorganic compounds requires the convergence of different theoretical formalisms or specific force fields. In the 1990s, the main concern of studies examining metalloporphyrins was the description of the metal-organic bonds in porphyrins. $^{124,129,130}$ 


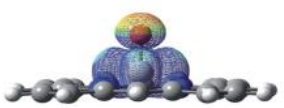

(a)

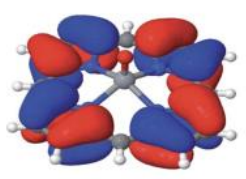

(c)

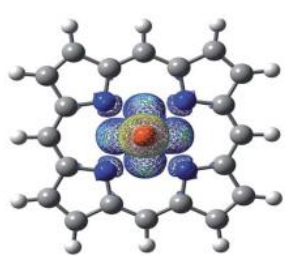

(b)

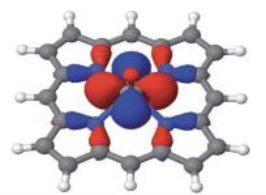

(d)

Figure 7. (a) and (b) Side and top views of the spin electronic density of a vanadyl porphyrin, respectively. (c) HOMO and (d) HOMO-2 molecular orbitals. Adapted from a reference. ${ }^{131}$

The evaluation of metal-organic bond energy was investigated more recently using quantum chemistry calculations. ${ }^{132}$ Finally, an accurate description of the electronic structure of metal-organic compounds requires the use of an adapted quantum chemistry formalism. In particular, metal elements present $d$ electrons that are strongly localized and thus require a methodology able to treat the electronic correlation accurately. Moreover, depending on the oxidation degrees of the metal, metal-organic compounds are generally open-shell systems that may present electronic states of different spin multiplicities in a short energy range. In that scope, vanadyl porphyrins are radicals, and an accurate description of the electronic structures of these compounds requires the implementation of multireference methodologies ${ }^{131}$, which are among the heaviest quantum chemistry calculations in terms of computational effort. For example, Figure 7 shows the molecular orbitals of vanadyl porphyrins. The unpaired electron is well localized on the vanadyl group, but the corresponding molecular orbital is not the HOMO orbital, which may provide a clue into the stability of the radical.

\section{- Structure of Metalloporphyrins}

The first attempt to consider metalloporphyrins using computational approaches concerns molecular mechanics studies of unique porphyrin molecules. ${ }^{124,128-130,133}$ These studies mainly perform conformational analyses of metalloporphyrins and compare the flat and ruffled conformations of porphyrins as a function of the metal center and substituents crafted on the pyrrolic core. The results were accompanied by the first development of reliable force fields able to reproduce the expected conformations. Two main approaches were envisaged to describe the metal-organic bonding. The first is the point in a sphere model ${ }^{124,130}$ where the metalligand bond is not explicitly included in the force field. The position of the metal in the porphyrin ring is provided by the size of the metal and the charges of the neighbors. This choice was not sufficiently accurate, and new force fields were developed that explicitly included the metal-ligand bond. ${ }^{129,130,134,135}$ The force fields were parametrized for $3 \mathrm{~d}$ row transition metals in general, including several oxidation degrees or spin states of the metal center separately and considering crystal structures as target properties. ${ }^{134}$ Researchers attempted to describe both the metal-organic bond inside the porphyrin and molecules with additional ligand molecules.

The first study to implement a quantum mechanical approach by Cundari et al. ${ }^{136}$ is also the first to consider vanadyl porphyrins. In their work, the authors used molecular mechanics and both semiempirical and Hartree- 
Fock methodologies to predict the structures of vanadium oxo-complexes that were consistent with experimental structures and provide stretching parameters for $\mathrm{V}-\mathrm{O}$ and $\mathrm{V}-\mathrm{N}$ bonds for several vanadium oxidation degrees and oxygen compositions. Later, the ruffling of nickel porphyrins was investigated using DFT calculations. ${ }^{137}$ The study includes an analysis of the contribution of the overlap between $\pi$ molecular orbitals to conformer stability. The proposed structures of nickel porphyrins and associated vibrational spectra computed from DFT calculations were also subjected to Raman and IR spectroscopy. ${ }^{138}$

More recently, the conformations of metalloporphyrins and substituted deformations were rationalized through a normal-mode analysis of a crystallographic database. ${ }^{125}$ This study provides a global overview of porphyrin conformations linked to metal centers and binding molecules.

\section{- Metalloporphryins and Intermolecular Interactions}

Intermolecular interactions are the microscopic driving force of global macroscopic behaviors. Using a bottomup approach, computational approaches are efficient methodologies to increase the knowledge of systems at a macroscopic scale from a microscopic description of the system. Based on that scope, the accuracy of force fields or quantum chemistry methodologies relies on their capacity to reflect these intermolecular interactions.

The first level is the characterization of the interaction between pairs of compounds including a metalloporphyrin. Considering only pairs of compounds or a few molecules allows the implementation of quantum chemistry calculations to investigate interactions between metalloporphyrins and a resin or asphaltene model molecules. ${ }^{70,139-142}$ In particular, a large effort provided an understanding of the contributions of $\pi$ stacking interactions ${ }^{142}$, hydrogen bonds ${ }^{70,140}$ or metal ligand interactions through direct bonding to the metal center. $^{70,139,141-143}$ These studies highlight the driving force of porphyrin behavior in asphaltene aggregates and the balance between $\pi$-stacking, hydrogen bonds and metal coordination. In the case of nickel porphyrins, a consensus is reached about the predominance of the typical association scheme through $\pi$-stacking interactions, ${ }^{140,141}$ and the axial binding onto the nickel center strongly depends on the electronic state of the nickel. ${ }^{70}$ For vanadyl porphyrins, both axial binding and $\pi$-stacking interactions are hindered by steric effects and the accessibility of the vanadium atom due to the out-of-plane conformation of the vanadyl group. ${ }^{70,140}$ Therefore, vanadyl porphyrins are not present between asphaltene molecular planes but rather bridge several nanoaggregates through side chain interactions and hydrogen bonds. ${ }^{144}$

Moreover, calculations show that asphaltene-asphaltene interaction energies are larger than asphalteneporphyrin interaction energies, which supports the hypothesis that trapped compounds and resins preferentially bind to porphyrins rather than asphaltenes in large aggregates. ${ }^{140,}{ }^{141}$ These conclusions were supported by molecular dynamics calculations that considered solvent effects, asphaltene diversity and thermodynamic conditions and concluded that metalloporphyrins do not directly affect asphaltene-asphaltene interactions. ${ }^{140,}$ 141, 144, 145 However, polar lateral chains on porphyrin core structures lead to hydrogen bond interactions with both asphaltenes and water, causing a reinforcement of $\pi$-stacking interactions between asphaltenes. Therefore, the presence of metalloporphyrins may display interfacial activity and, depending on the solvent, induce either stronger precipitation in $n$-heptane or stabilize aggregates at water/oil interfaces. ${ }^{141,144,145}$

Several studies have focused on the interaction between metalloporphyrins and solid surfaces. ${ }^{146-148}$ Adsorption onto surfaces is either undesirable due to side effects on the whole production chain or required for the formation of sieves or traps of metal compounds. These calculations implement periodic DFT calculations. A recent review presents a collection of periodic DFT calculations associated with metalloporphyrins for various applications. ${ }^{149}$ The adsorption of porphyrins and metalloporphyrins onto a fully hydroxylated (0001) surface of $\alpha$-quartz was investigated and compared with asphaltene, and adsorption 
energies of asphaltene molecules of the same order of magnitude as porphyrins were reported. ${ }^{148}$ However, this interaction is lower for metalloporphyrins, regardless of the metal center. ${ }^{148}$

\section{- Reactivity of Porphyrins}

In biological systems and particularly in enzymes, the heme cofactor is the catalytic center of a large number of chemical processes. Several groups have investigated the catalytic potential of petroleum-derived metalloporphyrins and their reactivity in crude oil. ${ }^{131}$ The binding energies of the metal center and the porphyrins were investigated to assess the stability of the organometallic complexes and routes of conversion reactions in catalytic systems. ${ }^{132,150}$ Vanadyl porphyrins possess the strongest binding energies, followed by nickel and iron. ${ }^{132}$

One of the interests in metal-porphyrin reactivity concerns the demetallization steps achieved through hydrodemetallization or hydrotreatment, as reported for nickel porphyrins and vanadyl porphyrins. ${ }^{151,152}$ DFT calculations contributed to determining the more likely pathways for the hydrogenation of nickel porphyrins and the detection of the intermediate. ${ }^{151}$ The best catalysts may display both high hydrogenation and hydrogenolysis activities. Moreover, demetallization was recently achieved using microwave irradiation. ${ }^{152}$ The roles of microwave and electric field irradiation were investigated through DFT calculations of vanadyl and nickel porphyrins to probe the effect of the orientation and intensities of the sources. The inclusion of electric field irradiation during chemical treatments reduces the HOMO-LUMO gap of metalloporphyrins, which may facilitate metal removal. ${ }^{152}$

Another concern is the possibility that porphyrins poison catalysts. Due to its closed shell character, the interaction between nickel porphyrins and the catalyst is expected to be weak unless the system is promoted in low-lying excited states. ${ }^{153}$ In contrast, the reactivity of vanadyl porphyrins is higher due to their radical character in the ground state of the molecule ${ }^{154}$ or the ability to form hydrogen bonds with the acceptor through the oxygen atom. The interactions between vanadyl porphyrins and zeolite catalysts were investigated using several methodologies ranging from static calculations ${ }^{154}$ to quantum molecular dynamic simulations. ${ }^{147} \mathrm{~A}$ clear affinity between zeolite surfaces and vanadyl porphyrins, associated in particular with the preferential interaction with acid or hydroxyl groups of the surface rather than water molecules, was reported. ${ }^{147}$ Nevertheless, adsorption itself does not cause structural damage to the zeolite. Electronic transfer was characterized from the catalyst to metalloporphyrin, which may be the initial step leading to the degradation of the catalyst.

\section{- Joint Experimental and Theoretical Work}

Collaborative studies that combine experimental and theoretical methodologies have attracted increasing interest due to the complementary and synergistic character of the two approaches. Theoretical methodologies rely on experimental data for calibration and validation and can serve as predictive tools for structural, thermodynamic or spectroscopic information.

UV-visible spectra of porphyrins were intensively investigated from a computational perspective. ${ }^{126}$ Accurate knowledge of the optical properties of petroleum metalloporphyrins is one of the commonly used probes to detect the presence of metals in crude oil. The UV-visible spectra of vanadyl and nickel porphyrins were investigated through DFT and time-dependent DFT calculations, including implicit solvation models. ${ }^{70,139}$ The $^{2}$ effect of axial coordination and annellation agreed well with the experimental results and led to a better knowledge of the Soret band shifts that occur for porphyrins bound to other compounds. ${ }^{155}$ 
Computational approaches are also implemented to proceed to a conformational analysis of candidate ions for the interpretation of trapped ion mobility spectrometry (IMS) experiments. ${ }^{50}$ Starting from ions observed during TIMS-FT-ICR MS experiments, DFT calculations produce candidate structures of metal and free porphyrin ions through protonation of the nitrogen ring atoms or the oxygen atoms in vanadyl porphyrins. The analysis of the experimental results then proceeds using theoretical mobility values computed from a hard sphere scattering model. Although a higher accuracy of computed mobility is expected to fully interpret the results in case of high resolution IMS experiments, the methodology shows its capacity to suggest candidate ions that are consistent with measured mobility.

\section{Transformations of Porphyrins in Heavy Oil Processing}

Thermal cracking and catalytic cracking are two main processes that convert large hydrocarbon molecules into smaller fragments and are applied to heavy oil to produce vehicle fuels and petrochemical feedstocks from low-ranked and poor-quality hydrocarbons. ${ }^{156-159}$ The transformation of nickel and vanadium compounds in thermal cracking is rarely a concern for the petroleum industry because these metals remain in coke and do not affect the process or contribute to product quality. Zheng ${ }^{160}$ investigated the compositional changes in porphyrins in the hydropyrolysis of a Venezuelan heavy oil residue using GC-AED and ESI FT-ICR MS, which indicated that side chain breaking and aromatization occurred simultaneously at high temperature (Figure 8).
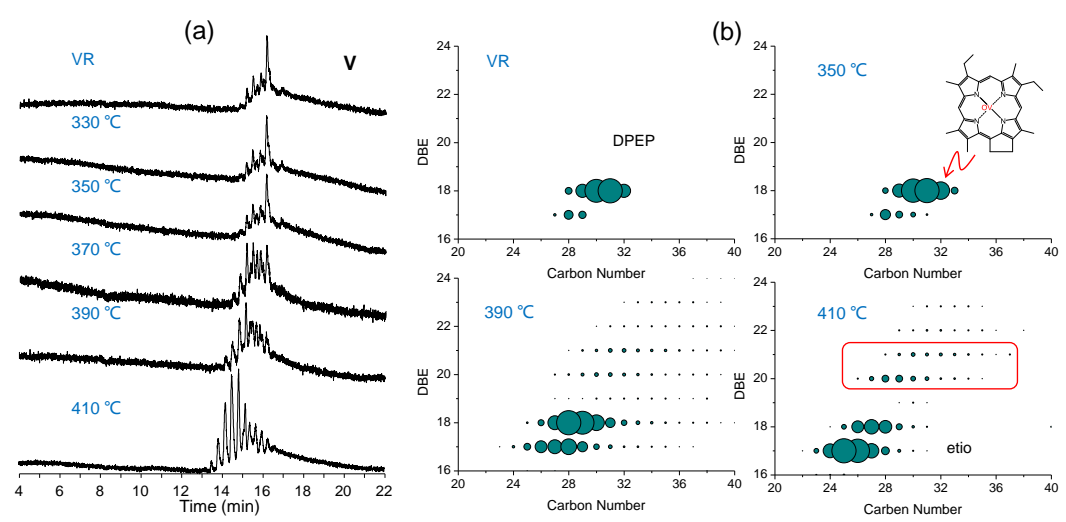

Figure 8. GC-AED (V) chromatograms (a) and DBE versus carbon number distribution of vanadyl porphyrins assigned from +ESI FT-ICR mass spectra $(b)$ of the Venezuelan heavy oil vacuum residual and its pyrolysis products at various temperatures. Adapted from a reference.(Zheng, 2021) Pyrolysis was conducted at 2 MP for $2 \mathrm{~h}$ in a hydrogen atmosphere. The figure was adapted from a previous study. ${ }^{160}$

Fluid Catalytic Cracking. Fluid catalytic cracking (FCC) is one of the most important processes applied worldwide to upgrade heavy petroleum fractions by converting them into lighter distillate products. ${ }^{161,162}$ Porphyrins were a major concern for FCC in the early days of petroleum refining, mainly due to the challenges associated with nickel and vanadium compounds in heavy oils. ${ }^{163}$ Nickel and vanadium atoms present in small organic compounds are not transferred into lighter fractions; therefore, the only destination for $\mathrm{Ni}$ and $\mathrm{V}$ compounds is forming coke on the catalyst, which leads to metal deposition, catalyst deactivation, and coke promotion during FCC processes. ${ }^{61,164}$ The greatest challenge is that the presence of vanadoxic acid produced by vanadium compounds destroys the catalyst skeleton, and thus the content of Ni/V in raw FCC feeds to less than $100 \mathrm{ppm}$ for vanadium to protect the catalyst and ensure normal FCC process operation, which is important because heavy oils that containing high $\mathrm{V} / \mathrm{Ni}$ concentrations have increased in production over the 
past decade. Importantly, a low $\mathrm{V} / \mathrm{Ni}$ content results in a lower operation cost and higher product quality; therefore, demetallization by hydrotreatment has been widely adopted in heavy oil processing. ${ }^{165-169}$

Hydrodemetallization. In contrast to FCC, the transformation mechanism of nickel and vanadium compounds is very important for catalyst design and the optimization of process conditions in hydrogenation processes. Many studies have been carried out on the hydrodemetallization mechanism with model compounds and real samples. Porphyrins were proposed to be converted into hydrogenated species before demetallation; however, direct experimental evidence was not available because the intermediates are not easy to characterize using traditional technologies. Recently, FT-ICR MS was used for the characterization of hydrotreated intermediates of nickel ${ }^{151}$ and vanadyl ${ }^{61}$ porphyrins with the model compound octaethylporphyrin (OEP). Dihydrogenated and tetrahydrogenated porphyrins were clearly detected in the ESI mass spectra, and their contents were quantified in the products obtained with oxidic and sulfidated $\mathrm{NiMo} / \mathrm{Al}_{2} \mathrm{O}_{3}$ catalysts, respectively. The structure of Ni-OEPH2 was speculated to be 1,2-dihydro-Ni-OEPH2, which was further hydrogenated into NiOEPH4. Tetrahydrogenated species are more unstable and easily demetallized. ${ }^{151}$ The main pathway of Ni/VOEP conversion during hydrotreatment was the hydrodemetallization route, and $\mathrm{Ni}$ was removed through rapid porphyrin ring fragmentation. VO tetrahydrogenated porphyrins are more unstable than their Ni counterparts, which decompose at room temperature. ${ }^{61,164}$ In addition, polar porphyrins are more prone to hydrogenation than nonpolar porphyrins. ${ }^{61}$

\section{- Challenges and Limitations of MS for nonporphyrin characterization}

A challenge always exists in the characterization of petroleum porphyrins: the composition and structure of nonporphyrins. Nonporphyrins are defined as a nickel or vanadium compound without discernible visible absorption spectrum in a UV-vis analysis that is nonvolatile. ${ }^{29}$ Nonporphyrins generally account for more than $\sim 50 \%$ of the elemental content of $\mathrm{Ni} / \mathrm{V}$, although these compounds also are unable to be characterized directly using MS. Despite decades of controversy, the presence of vanadyl and nickel nonporphyrin compounds has been speculated for years. ${ }^{170-172}$

Yen ${ }^{173}$ proposed nonporphyrins as coordination compounds, in which multiheteroatoms are coordinated with nickel and vanadium atoms. However, this assumption has never been proven based on molecular compositional evidence. Zhao et al. tried to provide mass spectral evidence of nonporphyrins, since FT-ICR MS is capable of characterizing petroleum porphyrins. ${ }^{36,37}$ The authors identified a series of porphyrins with additional oxygen functional groups, and in subsequent studies, an increasing number of nonporphyrin fractions were detected that contained nickel and vanadium atoms with porphyrin core structures. Substituent groups might change the optical and spectral behaviors from those of typical porphyrin complexes.

Wu et al. ${ }^{174}$ added $\mathrm{NH}_{4} \mathrm{COOH}$ to a nonporphyrin-enriched fraction of Venezuelan heavy oil and analyzed by +ESI MS. Strong MS signals from VO compounds were detected in the FT-ICR mass spectrum (Figure 9). ${ }^{174}$ These compounds have porphyrin compositions and distributions similar to those of the porphyrin fraction. The results imply the presence of nonporphyrins in the Venezuelan heavy oil, at least some of which are aggregates of porphyrins with other molecules. $\mathrm{NH}_{4} \mathrm{COOH}$ destroyed the aggregates and released free porphyrins. ${ }^{174}$

Moulian et al. ${ }^{175}$ investigated the effect of silver ions on the interaction between vanadium and asphaltene nanoaggregates using gel permeation chromatography and inductively coupled plasma high-resolution mass spectrometry (GPC ICP-HR-MS). Disaggregation of some vanadium compounds occurred when silver ions 
were added. ${ }^{175}$ In other words, the presence of silver ions changed the nonporphyrins and led to an increase in the free porphyrin content.

Zheng et al. ${ }^{176}$ characterized vanadyl porphyrins in heavy crude oil using ion mobility spectrometry. A series of mobiligram peak cluster ions was observed in the extracted ion mobility spectra of the porphyrins, which may contain an amine in the ions. Experimental results from model compounds indicate that all porphyrins tend to form adduct ions in electrospray ionization, such as $[2 \mathrm{M}]^{+},[2 \mathrm{M}+\mathrm{H}]^{+},[2 \mathrm{M}+\mathrm{Na}]^{+}$and clusters of ions of porphyrin with other compounds. This result implies the strong molecular aggregation potential of porphyrins with themselves and other petroleum molecules. The results are instructive for understanding the structure of nonporphyrins, although much remains unknown. ${ }^{176}$

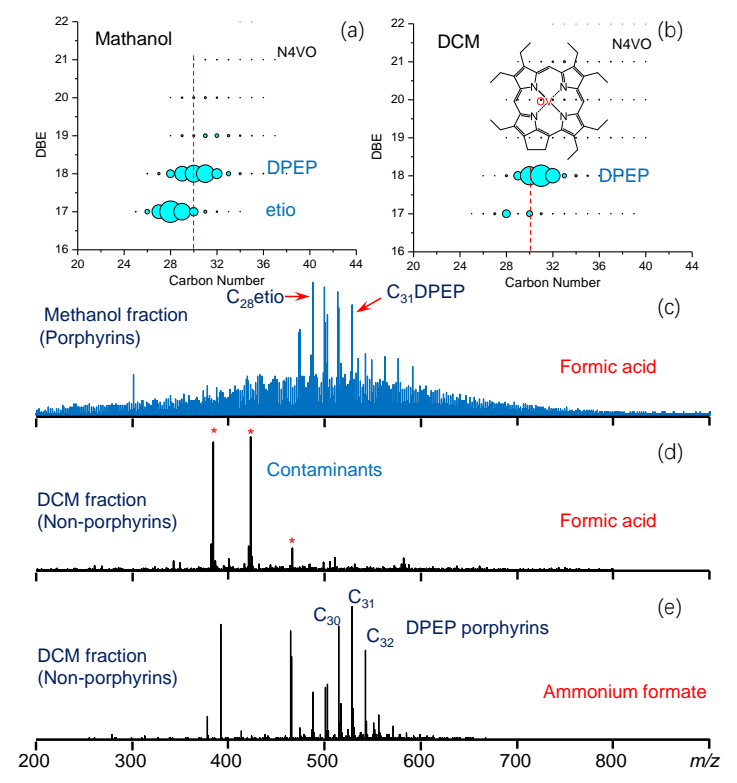

Figure 9. Porphyrins detected in the Venezuelan heavy oil fractions using +ESI FT-ICR MS. Vanadyl porphyrins assigned from the mass spectra of the porphyrin fraction (a) and nonporphyrin fraction (b). + ESI FT-ICR mass spectra of the porphyrin fraction $(c)$ and nonporphyrin fraction $(d)$ with formic acid and the nonporphyrin fraction with ammonium formate as the ionization promoter (e). Venezuelan heavy oil was loaded on diatomite and sequentially extracted with hexane, methanol, and dichloromethane (DCM). Porphyrins and nonporphyrins were enriched in the methanol and DCM fractions, respectively. The figure is adapted from previous studies. ${ }^{174,177}$

\section{- Application of Porphyrin Biomarkers for Geochemical Applications}

Porphyrins are the molecular fossils of bacteriochlorophylls, and thus the nitrogen composition provides quantitative information about the dominant phototrophs in past ecosystems. ${ }^{18,}{ }^{178-181}$ Early studies performed more than three decades ago resulted in an upsurge in geoporphyrin research that reported DPEP to etio porphyrin ratios as maturity indicators; specifically, structural alterations of porphyrins with increased catagenesis during petroleum maturation occurs through (a) dealkylation of alkyl side chains (thus shifting to a lower carbon number across a homologous series) and (b) a gradual change from DPEP to etio as the dominant structure. ${ }^{1,4,5,170,180,182}$ In addition, sedimentary porphyrins have been widely applied to trace biogeochemical processes related to past photoautotrophic activity in organic-rich sediments, shales and 
petroleum since the structural characteristics of porphyrins reflect the source chloropigment precursors and diagenetic transformation. ${ }^{1,180,183-190}$ In addition, the stable isotopic compositions of nitrogen and carbon in geoporphyrins provide critical information on source organisms. ${ }^{138,146,188,191-195}$

A few recent applications of methods for determining the porphyrin molecular composition and assessing biogeochemical processes are highlighted below. Based on FT-ICR MS, petroporphyrins were identified in 1.1-billion-year-old marine sedimentary rocks, and the authors concluded that the ocean was dominated by cyanobacteria. ${ }^{196}$ Molecular characterization of intact porphyrins (the molecular fossils of chlorophylls) was measured from 1,100-million-year-old marine black shales of the Taoudeni Basin (Mauritania), which were 600 million years older than previous findings (Figure 10). ${ }^{196}$
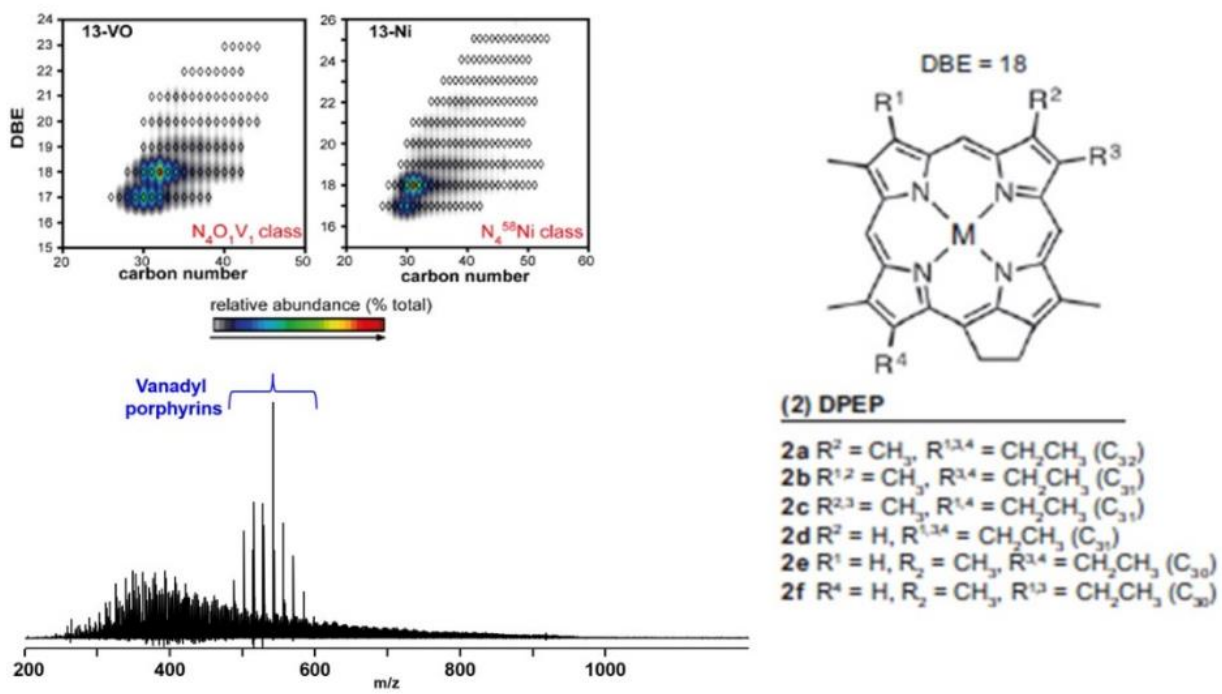

Figure 10. Bottom left panel: Broadband positive-ion atmospheric pressure photoionization (APPI) 9.4-tesla FT-ICR mass spectrum from a Mesoproterozoic shale extract from the Taoudeni Basin that detects more than 66,000 unique elemental compositions across a molecular weight range from $\mathrm{m} / \mathrm{z} 200-1200$ with achieved mass resolving power ( $\mathrm{m} / \Delta \mathrm{m} 50 \%$ ) of 1,200,000 at $\mathrm{m} / \mathrm{z}$ 500. Top left panel: Identification of two classes of $\mathrm{Ni}$ - and VO-porphyrins by FT-ICR MS in a graph plotting relative abundance versus doublebond equivalents (DBEs) and carbon number. Right panel: The structure of $C_{30}$ to $C_{32} D P E P$, one of the many porphyrin structures identified, supports phototrophs as dominant photosynthesizing organisms on Earth 1.1 billion years ago. Identified porphyrins were likely derived from oxygenic phototrophs and anoxygenic phototrophic bacteria. The figure was adopted from a previous study. ${ }^{196}$

Grosjean et al. ${ }^{197}$ investigated weathering effects on the organic matter composition from the surface to $10 \mathrm{~m}$ in the Paris Basin and reported the severe degradation of nickel and vanadyl porphyrins at the surface by substantial modification of their composition with preferential degradation of porphyrins with exocyclic rings compared to polyalkylporphyrins through weathering. ${ }^{197}$ Compared to laboratory oxidation experiments, the authors conclude that abiotic oxidation is the predominant mechanism responsible for sedimentary porphyrin alteration. ${ }^{197}$ Vanadyl porphyrins fractionated from gilsonite with high vanadium content (up to $3888 \mu \mathrm{g} / \mathrm{g}$ ) obtained from Sichuan Province, China, contain a large number of DPEP porphyrins, which indicates high molecular condensation but low thermal maturity, properties that are important for the efficient utilization of this natural source. ${ }^{198}$ A method to quantitate $\mathrm{Cu}, \mathrm{Ni}, \mathrm{VO}, \mathrm{Zn}$ and $\mathrm{Mn}$ porphyrins in geological samples was reported by Woltering et al., ${ }^{59}$ and the authors identified a range of additional compounds, such as an isobutyl $\mathrm{C}_{34} \mathrm{VO}$ porphyrin indicative of paleoenvironmental photic zone euxinia and several $\mathrm{Cu}$ and $\mathrm{Zn}$ 
porphyrins. This method combines HPLC coupled to an Orbitrap mass spectrometer, which allows the simultaneous quantitation of a wide range of metalloporphyrins without the need for demetallation or fractionation. ${ }^{59}$

\section{口 Conclusions}

Targeted analysis of petroporphyrins in crude oils is possible by employing selective ionization strategies such as ET MALDI. Controlling the matrix IE is fundamental to guide the ionization of the analyte and to prevent the ionization of molecules in the sample with an IE higher than the matrix. As expected, metalloporphyrin separation and isolation in samples of adequate purity requires long and tedious protocols, a feature that appears to be consequence of the relatively high amounts of porphyrins trapped within asphaltene noncovalent aggregates. ET-MALDI results in fewer interfering signals and improved analytical figures of merit. Computational approaches, including both quantum mechanics calculations and molecular dynamics simulations, have been implemented to investigate the behavior or intrinsic properties of petroporphyrins. The results help to elucidate the roles of these specific compounds in a synergetic way with experimental data, allowing us to obtain insights into nonreachable information experimentally. Such a multitechnique approach might be pursued and encouraged to further characterize these compounds and determine the accuracy of the interpretation. Although substantial advances in the characterization of porphyrins in geochemical systems have been facilitated by chemical information provided by advanced analytical techniques such as FT-ICR mass spectrometry, much remains for future researchers to investigate the role of porphyrins in asphaltene aggregation and the detection and characterization of nonporphyritic species. We present this review article in special recognition of Alan G. Marshall and his research collaborators over the years, who have enabled molecular characterization of these compounds at unprecedented detail.

\section{AUTHOR INFORMATION}

\section{Corresponding Author: Amy M. McKenna}

Phone: +18506444809 (AMM)

Fax: +18506441366

E-mail: mckenna@magnet.fsu.edu

Ion Cyclotron Resonance Program

National High Magnetic Field Laboratory

Florida State University

1800 East Paul Dirac Dr.

Tallahassee, Florida 32310-4005, United States

\section{Martha L. Chacón-Patiño}

Phone: +1 8506441319

Fax: +1 8506441366

E-mail: chacon@magnet.fsu.edu

Ion Cyclotron Resonance Program

National High Magnetic Field Laboratory

Florida State University

1800 East Paul Dirac Dr.

Tallahassee, Florida 32310-4005, United States

\section{Germain Salvato Vallverdu}

Phone: ++33559407851

E-mail: germain.vallverdu@univ-pau.fr 
Institut des Sciences Analytiques et de Physico-Chimie pour l'Environnement et les Materiaux Universite de Pau et des Pays de l'Adour, E2S UPPA, CNRS, IPREM, UMR5254, Hélioparc, 64053 Pau, France

International Joint Laboratory C2MC, Complex Matrices Molecular Characterization Total Research \& Technology Gonfreville BP 27, F-76700

Harfleur, France

\section{Brice Bouyssiere}

Phone: + 33559407752

E-mail: brice.bouyssiere@univ-pau.fr

Institut des Sciences Analytiques et de Physico-Chimie pour l'Environnement et les Materiaux Universite de Pau et des Pays de l'Adour, E2S UPPA, CNRS, IPREM, UMR5254, Hélioparc, 64053 Pau, France

International Joint Laboratory C2MC

Complex Matrices Molecular Characterization

Total Research \& Technology Gonfreville, BP 27, F-76700 Harfleur, France

\section{Pierre Giusti}

Phone: +33 235551432

E-mail: pierre.giusti@totalenergies.com

ORCID: 0000-0002-9569-3158

Total Research \& Technology Gonfreville

BP 27, F-76700

Harfleur, France

\section{Carlos Afonso}

Phone: +33 235522940

E-mail: carlos.afonso@univ-rouen.fr

Normandie Université

COBRA, UMR 6014 et FR 3038

Université de Rouen, INSA de Rouen-Normandie,

CNRS, IRCOF, Mont Saint Aignan Cedex

International Joint Laboratory C2MC

Complex Matrices Molecular Characterization

Total Research \& Technology, Gonfreville, BP 27, F-76700

Harfleur, France

\section{Quan Shi}

Phone: +8610 89739157

Email: sq@cup.edu.cn

ORCID: 0000-0002-1363-1237

State Key Laboratory of Heavy Oil Processing

China University of Petroleum, 
Beijing 102249 China

\author{
Marianny Y Combariza \\ Phone: +57 76344000 \\ Email: marianny@uis.edu.co \\ Escuela de Química \\ Universidad Industrial de Santander \\ Bucaramanga, 680002, Colombia
}

\title{
ACKNOWLEDGMENTS
}

This work was supported by the NSF Division of Chemistry and Division of Materials Research through DMR-1644779 and the State of Florida. MYC acknowledges the Guatiguará Technology Park and the Mass Spectrometry Lab - Central Research Laboratory Facility at Universidad Industrial de Santander for infrastructural assistance and the Colombian Ministry of Science, Technology, and Innovation for financial support. QS was supported by the National Science Foundation of China through grant NSFC U19B2002. CA acknowledges financial support from CNRS FTICR research infrastructure (FR3624), European Union's Horizon 2020 Research Infrastructures program (731077) and Laboratoire d'Excellence (LabEx) SynOrg (ANR-11-LABX-0029).

\section{口 REFERENCES}

1. Baker, E. W.; Louda, J. W.; Orr, W. L., Application of metalloporphyrin biomarkers as petroleum maturity indicators: The importance of quantitation. Org. Geochem. 1987, 11, (4), 303-33-309.

2. Biesaga, M.; Pyrzynska, K.; Trojanowicz, M., Porphyrins in analytical chemistry. A review. Talanta 2000, 51, (2), 209-29-224.

3. $\quad$ Milgrom, L. R., The coulours of life: An introduction to the chemistry of porphyrins and related compounds. Oxford University Press: Oxford, U.K., 1999.

4. Baker, E. W., Mass spectrometric characterization of petroporphyrins. J. Amer. Chem. Soc. 1966, 88, (10), 2311-21-2311.

5. $\quad$ Baker, E. W.; Yen, T. F.; Dickie, J. P.; Rhodes, R. E.; Clark, L. F., Mass spectrometry of porphyrins. II. Characterization of petroporphyrins. J. Amer. Chem. Soc. 1967, 89, (4), 3631-31-3639.

6. Ali, M. F.; Abbas, S., A review of methods for the demetallization of residual fuel oils. Fuel Process.Technol. 2006, 87, 573-53-584.

7. Dodds, J. N.; Baker, E. S., Ion mobility spectrometry: Fundamental concepts, instrumentation, applications and the road ahead. J. Am. Soc. Mass Spectrom. 2019, 30, 2185-25-2195.

8. Treibs, A., Occurrence of chlorophyll derivatives in an oil shale of the upper Triassic. Justus Liebigs Ann. Chem. 1934, 509, 103-13-114.

9. Treibs, A., Organic mineral substances. V. Porphyrins in coals. Justus Liebigs Ann. Chem. 1935, 520, 144-14-150.

10. Treibs, A., Organic mineral substances. IV. Chlorophyll and hemin derivatives in bituminous rocks, petroleums, coals and phosphorites. Justus Liebigs Ann. Chem. 1935, 517, 172-12-196.

11. Treibs, A., Chlorophyll and hemin derivatives in organic mineral substances. Angew. Chemie 1936, 49, (38), 682-62-686.

12. Dechaine, G. P.; Gray, M. R., Chemistry and association of vanadium compounds in heavy oil and bitumen, and implications for their selective removal. Energy Fuels 2010, 24, (5), 2795-25-2808. 
13. Ramírez-Pradilla, J. S.; Blanco-Tirado, C.; Hubert-Roux, M.; Giusti, P.; Afonso, C.; Combariza, M. Y., Comprehensive Petroporphyrin Identification in Crude Oils Using Highly Selective Electron Transfer Reactions in MALDI-FTICR-MS. Energy Fuels 2019, 33, (5), 3899-39-3907.

14. Hodgson, G. W.; Peake, E., Metal chlorin complexes in recent sediments as initial precursors to petroleum porphyrin pigments. Nature 1961, 191, 766.

15. Sundararaman, P., On the mechanism of change in DPEP/ETIO ratio with maturity. Geochim. Cosmochim. Acta 1993, 57, 4517-47-4520.

16. Filby, R. H.; van Berkel, G. J. Geochemistry of source metal and complexes in petroleum, coals: A overview rocks. Washington State University, Pullman, WA 99164-14-1300, 1987.

17. Lash, T. D., Geochemical origins of sedimentary benzoporphyrins and tetrahydrobenzoporphyrins. Energy Fuels 1993, 7, 166-16-171.

18. Thomas, D. W.; Blumer, M., Porphyrin pigments of a Triassic sediment. Geochim. Cosmochim. Acta 1964, 28, (7), 1147-1154.

19. Hajibrahim, S. K.; Quirke, J. M. E.; Eglinton, G., Petroporphyrins V. Structurally-related porphyrin series in bitumens, shales and petroleum- Evidence from HPLC and mass spectrometry. Chem. Geol. 1981, 32, 173-13-188.

20. Quirke, J. M. E.; Maxwell, J. R.; Eglinton, G., Petroporphyrins. V. Structurally-related porphyrin series in bitumens, shales and petroleums- evidence from HPLC and mass spectrometry. Chem. Geol. 1981, 32, (1-41-4), 173-13-188.

21. Ekstrom, A.; Fookes, C. J. R.; Hambley, T.; Loeh, H. J.; Miller, S. A.; Taylor, J. C., Determination of the crystal structure of a petroporphyrin isolated from oil shale. Nature 1980, 306, (5939), 173-13-174.

22. Zhang, Y.; Schulz, F.; McKay Rytting, B.; Walters, C. C.; Kaiser, K.; Metz, J. N.; Harper, M. R.; Merchant, S. S.; Mennito, A. S.; QIan, K.; Kushnerick, J. D.; Kilpatrick, P. K.; Gross, L., Elucidating the geometric substitution of petroporphyrins by spectroscopic analysis and atomic force microscopy molecular imaging. Energy Fuels 2019, 33, 6088-68-6097.

23. Zheng, F.; Shi, Q.; Vallverdu, G. S.; Giusti, P.; Bouyssiere, B., Fractionation and Characterization of Petroleum Asphaltene: Focus on Metalopetroleomics. Processes 2020, 8, (1504), 1-31-31.

24. Mironov, N. A.; Milordov, D. V.; Abilova, G. R.; Yakubova, S. G.; Yakubov, M. R., Methods for studying petroleum porphyrins (Review). Pet. Chem. 2019, 59, (10), 1077-17-1091.

25. Gallegos, E. J.; Sundararaman, P., Mass spectrometry of geoporphyrins. Mass Spectrom. Rev. 1985, 4, 55-85-85.

26. Rodgers, R. P.; McKenna, A. M., Petroleum analysis. Anal. Chem. 2011, 83, 4665-45-4687.

27. Kim, S.; Kim, D.; Jung, M.-J.; Kim, S., Analysis of environmental organic matters by Ultrahigh-

Resolution mass spectrometry-A review on the development of analytical methods. Mass Spec. Rev. 2021, 1-11-18.

28. Bonnett, R., Porphyrins in coal. Int. J. Coal Geol. 1996, 32, 137-17-149.

29. Zhao, X.; Xu, C.; Shi, Q., Porphyrins in Heavy Petroleums: A Review. Struct. Bond. 2016, 168, 3979-70.

30. Rodgers, R. P.; Hendrickson, C. L.; Emmett, M. R.; Marshall, A. G.; Greaney, M. A.; Qian, K., Molecular Characterization of Petroporphyrins in Crude Oil by Electrospray Ionization Fourier Transform Ion Cyclotron Resonance Mass Spectrometry. Can. J. Chem. 2001, 79, 546-56-551.

31. McKenna, A. M.; Purcell, J. M.; Rodgers, R. P.; Marshall, A. G., Identification of vanadyl porphyrins in a heavy crude oil and raw asphaltene by atmospheric pressure photoionization Fourier transform ion cyclotron resonance (FT-ICR) mass spectrometry. Energy Fuels 2009, 23, (4), 2122-22-2128.

32. McKenna, A. M.; Williams, J. T.; Putman, J. C.; Aeppli, C.; Reddy, C. M.; Valentine, D. L.; Lemkau, K. L.; Kellerman, M. Y.; Savory, J. J.; Kaiser, N. K.; Marshall, A. G.; Rodgers, R. P., Unprecedented ultrahigh resolution FT-ICR mass spectrometry and parts-per-billion mass accuracy enable 
direct characterization of nickel and vanadyl porphyrins in petroleum from natural seeps. Energy Fuels 2014, 28, 2454-24-2464.

33. Qian, K.; Mennito, A. S.; Edwards, K. E.; Ferrughelli, D. T., Observation of vanadyl porphyrins and sulfur-containing vanadyl porphyrins in a petroleum asphaltene by atmospheric pressure photonionization Fourier transform ion cyclotron resonance mass spectrometry. Rapid Commun. Mass Spectrom. 2008, 22 , (14), 2153-23-2160.

34. Qian, K.; Edwards, K. E.; Mennito, A. S.; Walters, C. C.; Kushnerick, J. D., Enrichment, Resolution, and Identification of Nickel Porphyrins in Petroleum Asphaltene by Cyclograph Separation and Atmospheric Pressure Photoionization Fourier Transform Ion Cyclotron Resonance Mass Spectrometry. Anal. Chem. 2010, 82, (1), 413-43-419.

35. Zheng, F.; Hsu, C. S.; Zhang, Y.; Sun, Y.; Wu, Y.; Lu, H.; Sun, X.; Shi, Q., Simultaneous detection of vanadyl, nickel, iron and gallium porphyrins in marine shales from the Eagle Ford formation, South Texas. Energy Fuels 2018, 32, (10), 10382-12-10390.

36. Zhao, X.; Liu, Y.; Xu, C.; Yan, Y.; Zhang, Y.; Zhang, Q.; Zhao, S.; Chung, K.; Gray, M. R.; Shi, Q., Separation and characterization of vanadyl porphyrins in Venezuela Orinoco heavy crude. Energy Fuels 2013, 27, (6), 2874-24-2882.

37. Zhao, X.; Shi, Q.; Gray, M. R.; Xu, C., New vanadium compounds in Venezuela heavy crude oil detected by positive-ion electrospray ionization fourier transform ion cyclotron resonance mass spectrometry. Sci. Rep. 2014, 4, (5373).

38. Qian, K.; Fredriksen, T. R.; Mennito, A. S.; Zhang, Y.; Harper, M. R.; Merchant, S.; Kushnerick, J. D.; Rytting, B. M.; Kilpatrick, P. K., Evidence of naturally-occurring vanadyl porphyrins containing multiple $\mathrm{S}$ and $\mathrm{O}$ atoms. Fuel 2019, 239, 1258-18-1264.

39. Faramawy, S.; El-Sabagh, S. M.; Moustafa, Y. M.; El-Naggar, A. Y., Mass spectrometry of metalloporphyrins in Egyption oil shales from Red Sea area. Petr. Sci. Technol. 2010, 28, (6), 603-63-617. 40. Jarvis, J. M.; Sudasinghe, N. M.; Albrecht, K. O.; Schmidt, A. J.; Hallen, R. T.; Anderson, D. B.; Billing, J. M.; Schaub, T. M., Impact of iron porphyrin complexes when hydroprocessing algal HTL biocrude. Fuel 2016, 182, 411-41-418.

41. Putman, J. C.; Rowland, S. M.; Corilo, Y. E.; McKenna, A. M., Chromatographic enrichment and subsequent separation of nickel and vanadyl porphyrins from natural seeps and molecular characterization by positive electrospray ionization FT-ICR mass spectrometry. Anal. Chem. 2014, 86, (32), 10708-18-10715. 42. Suwarno, A. C.; Yulizar, Y.; Haerudin, H.; Kurniawaty, I.; Apriandanu, D. O. B., Investigation of metalloporphyrin in maltenes phase of crude oil Duri. Journal of Physics: Conference Series 2020, (1442), 012049.

43. McDaniel, E.; Martin, D. W.; Barnes, W. S., Drift tube-mass spectrometer for studies of low-energy ion-molecule reactions. Rev. Sci. Instrum. 1962, 33, (1), 2-72-7.

44. Campuzano, I.; Bush, M. F.; Robinson, C. V.; Beaumont, C.; Richardson, K.; Kim, H.; Kim, I., Structural characterization of drug-like compounds by ion mobility mass spectrometry: Comparison of theoretical and experimentally dervied nitrogen collision cross sections. Anal. Chem. 2012, 84, (2), 1026-161033.

45. Kailemia, M. J.; Park, M.; Kaplan, D. A.; Venot, A.; Boons, G. J.; Li, L.; Linhardt, R. J.; Amster, I. J., High-field asymmetric-waveform ion mobility spectrometry and electron detachment dissociation of isobaric mixtures of glycosaminoglycans. J. Am. Soc. Mass Spectrom. 2014, 25, (2), 258-28-268.

46. Benigni, P.; Marin, R.; Fernandez-Lima, F. A., Towards unsupervised polyaromatic hydrocarbons strucutral assignment from SA-TIMS-FTMS data. Int. J. Ion Mobil. Spectrom. 2015, 18, (3), 151-11-157. 47. Benigni, P.; Fernandez-Lima, F. A., Oversampling Selective Accumulation Trapped Ion Mobility Spectrometry Coupled to FT-ICR MS: Fundamentals and Applications. Anal. Chem. 2016, 88, (14), 740474-7412. 
48. Mason, E. A.; Schamp, H. W., Mobility of gaseous ions in weak electric fields. Annals of Physics 1958, 4, (3), 233-23-270.

49. Zheng, F.; Zhang, Y.; Zhang, Y.; Y., H.; Zhang, L., Aggregation of petroporphyrins and fragmentation of porphyrin ions: Characterized by TIMS-TOF MS and FT-ICR MS. Fuel Bouyssiere, B. Shi, Q., 289, 119889.

50. Benigni, P.; Bravo, C.; Quirke, J. M. E.; DeBord, J. D.; Mebel, A. M.; Fernandez-Lima, F. A., Analysis of geologically relevant metal porphyrins using trapped ion mobility spectrometry-mass spectrometry and theoretical calculations. Energy Fuels 2016, 30, (12), 10341-11-10347.

51. Maillard, J. F.; Le Maître, J.; Rüger, C.; Ridgeway, M. E.; Thompson, C. J.; Paupy, B.; Hubert-Roux, M.; Park, M. A.; Afonso, C.; Giusti, P., Structural analysis of petroporphyrins from asphaltene by trapped ion mobility coupled with a Fourier transform ion cyclotron resonance mass spectrometer. Analyst 2021. 52. Smith, D. F.; Blakney, G. T.; Beu, S. C.; Anderson, L. C.; Weisbrod, C. R.; Hendrickson, C. L., Ultrahigh resolution ion isolation by stored waveform inverse Fourier transform $21 \mathrm{~T}$ Fourier transform ion cyclotron resonance mass spectrometry. Anal. Chem. 2020, 92, (4), 3213-33-3219.

53. Beato, B. D.; Yost, R. A.; Quirke, J. M. E., Doubly charged porphyrin ion tandem mass spectrometry: Implications for structure elucidation. Org. Mass Spectrometry 1989, 24, (10), 875-85-884.

54. Johnson, J. V.; Britton, E. D.; Yost, R. A.; Quirke, J. M. E.; Cuesta, L. L., Tandem mass spectrometry for characterization of high-carbon number geoporphyrins. Anal. Chem. 1986, 58, (7), 132515-1329.

55. Beato, B. D.; Yost, R. A.; Quirke, J. M. E., Carbon number, pyrrolic structure and sequencing information of porphyrin structure in one experiment by desorption tandem mass spectrometry-relevance for geoporphyrins. Chem. Geol. 1991, 91, (2), 185-15-192.

56. Laycock, J. D.; Ferguson, J. A.; Yost, R. A.; Quirke, J. M. E.; Rohrer, A.; O'Campo, R.; Callot, H. J., Electron ionization mass spectrometric analysis of 5-nitro octaethylporphyrin: Evidence for scission of the porphyrin macrocycle. J. Mass Spectrom. 1988, 32, (9), 978-983.

57. Van Berkel, G. J.; McLuckey, S. A.; Glish, G. L., Unimolecular and collision-induced reactions of doubly charged porphyrins. J. Am. Soc. Mass Spectrom. 1992, 3, (3), 235-25-242.

58. Rosell-Mele, A.; Carter, J. F.; Maxwell, J. R., HIgh-performance liqud chromatogrpahy-mass spectrometry of porphyrins by using an atmospheric pressure interface. J. Am. Soc. Mass Spectrom. 1996, 7 , 965-95-971.

59. Woltering, M.; Tulipani, S.; Boreham, C. J.; Walshe, J.; Schwark, L.; Grice, K., Simultaneous quantitative analysis of $\mathrm{Ni}, \mathrm{VO}, \mathrm{Cu}, \mathrm{Zn}$ and $\mathrm{Mn}$ geoporphyrins by liquid chromatography-high resolution multistage mass spectrometry: Method development and validation. Chemical Geology 2016, 441, 81-91-91. 60. Xu, H.; Que, G.; Yu, D.; Lu, J. R., Characterization of petroporphyrins using ultraviolet-visibile spectroscopy and laser desorption ionization time-of-flight mass spectrometry. Energy Fuels 2005, 19, (2), 517-57-524.

61. Liu, H.; Mu, J.; Wang, Z.; Ji, S.; Shi, Q.; Guo, A.; Chen, K.; Lu, J., Characterization of vanadyl and nickel porphyrins enriched from heavy residues by positive-ion electrospray ionization FT-ICR mass spectrometry. Energy Fuels 2015, 29, 4803-43-4813.

62. McLafferty, F. W.; Turecek, F., Interpretation of Mass Spectra, 4th ed. University Science Books: Mill Valley, CA, 1993.

63. Liu, T.; Lu, J.; Zhao, X.; Zhou, Y.; Wei, Q.; Xu, C.; Zhang, Y.; Ding, S.; Zhang, T.; Tao, X.; Ju, L.; Shi, Q., Distribution of vanadium compounds in petroleum vacuum residuum and their transformationsin hydrodemetallization. Energy Fuels 2015, 29, (4), 2089-2096.

64. Chauhan, G.; de Klerk, A., Acidified ionic liquid assisted recovery of vanadium and nickel from oilsands bitumen. Energy Fuels 2021, 35, (7), 5963-53-5974. 
65. Gascon, G.; Negrin, J.; Garcia-Montoto, V.; Acevedo, S.; Lienemann, C. P.; Bouyssiere, B., Simplification of heavy matrices by liquid-liquid extraction: Part 1- How to separate LMW, MMW, and HMW compounds in maltene fractions of V, Ni, and S compounds. Energy Fuels 2019, 33, (3), 1922-121927.

66. Zhang, Y.; Zhang, L.; Xu, Z.; Zhang, N.; Chung, K. H.; Zhao, S.; Xu, C.; Shi, Q., Molecular characterization of vacuum resid and its fractions by Fourier transform ion cyclotron resonance mass spectrometry with various ionization techniques. Energy Fuels 2014, 28, (12), 7488-78-7456.

67. Yin, C.-X.; Stryker, J. M.; Gray, M. R., Separation of petroporphyrins from asphaltenes by chemical modification and selective affinity chromatography. Energy Fuels 2009, 23, 2600-20-2605.

68. Yin, C.-X.; Stryker, J. M.; Gray, M. R., Separation of petroporphyrins from asphaltenes by chemical modification and selective affinity chromatography. Energy Fuels 2009, 23, (5), 2600-2605.

69. Acevedo, S.; Guzmán, K.; Labrador, H. C.; Bouyssiere, B.; Lobinski, R., Trapping of Metallic Porphyrins by Asphaltene Aggregates: A Size Exclusion Microchromatography With High-Resolution Inductively Coupled Plasma Mass Spectrometric Detection Study. Energy Fuels 2012, 26, (8), 4968-484977.

70. Stoyanov, S. R.; Yin, C.-X.; Gray, M. R.; Stryker, J. M.; Gusarov, S.; Kovalenko, A., Computational and experimental study of the structure, binding preferences, and spectroscopy of nickel(II) and vanadyl porphyrins in petroleum. J. Phys. Chem. B. 2010, 114, (6), 2180-20-2188.

71. Desprez, A.; Bouyssiere, B.; Arnaudguilhem, C.; Krier, G.; Vernex-Loset, L.; Giusti, P., Study of the Size Distribution of Sulfur, Vanadium, and Nickel Compounds in Four Crude Oils and Their Distillation Cuts by Gel Permeation Chromatography Inductively Coupled Plasma High-Resolution Mass Spectrometry. Energy Fuels 2014, 28, (6), 3730-30-3737.

72. Gascon, G.; Vargas, V.; Feo, L.; Castellano, O.; Castillo, J.; Giusti, P.; Acavedo, S.; Lienemann, C. P.; Bouyssiere, B., Size distributions of sulfur. vanadium, and nickel compounds in crude oils, residues, and their saturate, aromatic, resin, and asphaltene fractions determined by gel permeation chromatography inductively coupled plasma high-resolution mass spectrometry. Energy Fuels 2017, 31, (8), 7783-73-7788.

73. Putman, J. C.; Moulian, R.; Barrère-Mangote, C.; Rodgers, R. P.; Bouyssiere, B.; Giusti, P.;

Marshall, A. G., Probing Aggregation Tendencies in Asphaltenes by Gel Permeation Chromatography. Part 1: Online Inductively Coupled Plasma Mass Spectrometry and Offline Fourier Transform Ion Cyclotron Resonance Mass Spectrometry. Energy Fuels 2020, 34, (7), 8308-88-8315.

74. Hsu, C. S.; Lobodin, V. V.; Rodgers, R. P.; McKenna, A. M.; Marshall, A. G., Compositional boundaries for fossil hydrocarbons. Energy Fuels 2011, 25, (5), 2174-24-2178.

75. Putman, J. C.; Moulian, R.; Smith, D. F.; Weisbrod, C. R.; Chacón-Patiño, M. L.; Corilo, Y. E.; Blakney, G. T.; Rumancik, L. E.; Barrère-Mangote, C.; Rodgers, R. P.; Giusti, P.; Marshall, A. G.;

Bouyssière, B., Probing Aggregation Tendencies in Asphaltenes by Gel Permeation Chromatography. Part 2: Online Detection by Fourier Transform Ion Cyclotron Resonance Mass Spectrometry and Inductively Coupled Plasma Mass Spectrometry. Energy Fuels 2020, 34, (9), 10915-15-10925.

76. Altgelt, K. H., Fractionation of asphaltenes by gel permeation chromatography. J. Appl. Polym. Sci. 1965, 9, 3389-39-3393.

77. Coleman, H. J., Hirsch, D.E., Dooley, J.E., Separation of Crude Oil Fractions by Gel Permeation Chromatography. 1969, 6, 800-80-804.

78. Sata, S.; Takanohashi, T.; Tanaka, R., Molecular weight calibration using gel permeation chromatography/mass spectrometry. Energy \& Fuels 2005, 19, (5), 1991-11-1994.

79. Sato, S.; Takanohashi, T.; Tanaka, R., Molecular weight calibration of asphaltenes using gel permeation chromatography/mass spectrometry. Energy \& Fuels 2005, 19, (5), 1991-11-1994.

80. Putman, J. C.; Chacón-Patiño, M. L.; Rowland, S. M.; Weisbrod, C. R.; Smith, D. F.; Corilo, Y. E.; Barrer-Mangote, C.; Bouyssiere, B.; Giusti, P.; Rodgers, R. P.; Marshall, A. G. In Online Gel Permeation 
Chromatography/ / Fourier Transform Ion Cyclotron Resonance Mass Spectrometry: Probing Aggregation Tendencies in Asphaltenes and Petroleum Products, Petrophase, Salt Lake City, Utah July 8-18-12, 2018, 2018; Salt Lake City, Utah July 8-18-12, 2018, 2018.

81. Garcia-Montoto, V.; Verdier, S.; Maroun, Z.; Egeberg, R.; Tiedje, J. L.; Sanderson, S. S.; Zeuthen, P.; Bouyssiere, B., Understanding the removal of V, Ni and $\mathrm{S}$ in crude oil atmospheric residue hydrodemtallization and hydrodesulfurization. Fuel Process.Technol. 2020, 201, 106341.

82. Moulian, R.; Chacón-Patiño, M. L.; Lacroix-Andrivet, O.; Mounicou, S.; Mendes Siqueira, A. L.; Afonso, C.; Rodgers, R. P.; Giusti, P.; Bouyssiere, B.; Barrère-Mangote, C., Speciation of Metals in Asphaltenes by High-Performance Thin-Layer Chromatography and Solid-Liquid Extraction Hyphenated with Elemental and Molecular Identification. Energy Fuels 2020, 34, (10), 12449-19-12456.

83. Yin, C.-X.; Tan, X.; Klaus, M.; Stryker, J. M.; Gray, M. R., Associative $\pi-\pi$ Interactions of condensed aromatic compounds with vanadyl or nickel porphyrin complexes are not observed in the organic phase. Energy Fuels 2008, 22, (4), 2465-25-2469.

84. Chacón-Patiño, M. L.; Rowland, S. M.; Rodgers, R. P., Advances in asphaltene petroleomics. Part 2: A selective separation method that reveals fractions enriched in island and archipelago strucutral motifs by mass spectrometry. Energy Fuels 2018, 32, (1), 314-34-328.

85. Chacón-Patiño, M. L.; Rowland, S. M.; Rodgers, R. P., Advances in Asphaltene Petroleomics. Part 3. Dominance of island or archipelago structural motif is sample dependent. Energy Fuels 2018, 32, (9), 910696-9120.

86. Chacón-Patiño, M. L.; Smith, D. F.; Hendrickson, C. L.; Marshall, A. G.; Rodgers, R. P., Advances in Asphaltene Petroleomics. Part 4. Compositional Trends of Solubility Subfractions Reveal that Polyfunctional Oxygen-Containing Compounds Drive Asphaltene Chemistry. Energy Fuels 2020, 34, (3), 3013-33-3030.

87. Castellanos-Garcis, L. J.; Agudelo, B. C.; Rosales, H. F.; Cely, M.; Ochoa-Puentes, C.; BlancoTirado, C.; Sierra, C. A., Oligo p-Phenylenevinylene Derivatives as Electron Transfer Matrices for UVMALDI. J. Am. Soc. Mass Spectrom. 2017, 28, 2548-28-2560.

88. Giraldo-Dávila, D.; Chacón-Patiño, M. L.; Ramirez-Pradillia, J. S.; Blanco-Tirado, C.; Combariza, M. Y., Selective ionization by electron-transfer MALDI-MS of vanadyl porphyrins from crude oils. Fuel 2018, 226, 103-13-111.

89. Evdokimov, I. N.; Fesan, A. A.; Losev, A. P., Occlusion of foreign molecules in primary asphaltene aggregates from near-UV-Visible absorption studies. Energy Fuels 2017, 31, (2), 1370-10-1375.

90. Pereia, S. F. J.; Moraes, D. P.; Antes, F. G.; Diehl, L. O.; Santos, M. F. P.; Guimarães, R. C. L.; Fonseca, T. C. O.; Dressler, V. L.; Flores, E. M. M., Determination of metals and metalloids in light and heavy crude oil by ICP-MS after digestion by microwave-induced combustion. Microchem. J. 2010, 96, 414-11.

91. Fan, S.; Liu, H.; Wang, J.; Chen, H.; Bai, R.; Guo, A.; Chen, K.; Huang, J.; Wang, Z., Microwaveassisted Petroporphyrin Release from Asphaltene Aggregates in Polar Solvents. Energy Fuels 2020, 34, (3), 2683-23-2692.

92. Bjorndalen, N.; Islam, M. R., The effect of microwave and ultrasonic irradiation on crude oil during production with a horizontal well. J. Pet. Sci. Eng. 2004, 43, 139-19-150.

93. Xia, L.; Lu, S.; Cao, G., Stability and demulsifcation of emulsions stabilized by asphaltenes or resins. J. Colloid Interface Sci. 2004, 271, 504-54-506.

94. Kelemen, S. R.; Afeworki, M.; Gorbaty, M. L.; Sansone, M.; Kwiatek, P. J.; Walters, C. C.; Freund, H.; Siskin, M.; Bence, A. E.; Curry, D. J.; Solum, M.; Pugmire, R. J.; Vandenbroucke, M.; Leblond, M.; Behar, F., Direct characterization of kerogen by X-ray and Solid-State 13C Nuclear Magnetic Resonance methods. Energy Fuels 2007, 21, (3), 1548-18-1561. 
95. Siskin, M.; Kelemen, S. R.; Eppig, C. P.; Brown, L. D.; Afeworki, M., Asphaltene molecular structure and chemical influences on the morphology of coke produced in delayed coking. Energy Fuels 2006, 20, (3), 1227-17-1234.

96. Rytting, B. M.; Singh, I. D.; Kilpatrick, P. K.; Harper, M. R.; Mennito, A. S.; Zhang, Y., Ultrahighpurity vanadyl petroporphyrins. Energy FUels 2018, 32, (5), 5711-51-5724.

97. Rytting, B. M.; Harper, M. R.; Edmond, K. V.; Zhang, Y.; Kilpatrick, P. K., High-purity vanadyl petroporphyrins: Their aggregation and effect on the aggregation of asphaltenes. Energy Fuels 2020, 34, (1), 164-14-178.

98. Rytting, B. M.; Harper, M. R.; Edmond, K. V.; Merchant, S.; Zhang, Y.; Kilpatrick, P. K., Interfacial phenomena of purified petroporphyrins and their impact on asphaltene interfacial film formation. Energy Fuels 2020, 34, (5), 5444-54-5456.

99. Mironov, N. A.; Milordov, D. V.; Tazeeva, E. G.; Abilova, G. R.; Tazeev, D. I.; Morozov, V. I.; Yakubova, S. G.; Yakubov, M. R., Influence of the composition of the sulfuric acid cation exchanger on the efficiency of chromatographic purification of petroleum vanadyl porphyrins. Russ J. Appl. Chem. 2020, 93, 888-88-896.

100. Mironov, N. A.; Abilova, G. R.; Sinyashin, K. O.; Gryaznov, P. I.; Borisova, Y. Y.; Milordov, D. V.; Tazeeva, E. G.; Yakubov, S. G.; Borisov, D. N.; Yakubov, M. R., Chromatographic isolation of petroleum vanadyl porphyrins using sulfocationites as sorbents. Energy Fuels 2018, 32, 161-11-168.

101. Mironov, N. A.; Abilova, G. R.; Borisova, Y. Y.; Tazeeva, E. G.; Milordov, D. V.; Yakubova, S. G.; Yakubov, M. R., Comparative Study of Resins and Asphaltenes of Heavy Oils as Sources for Obtaining Pure Vanadyl Porphyrins by the Sulfocationite-Based Chromatographic Method. Energy Fuels 2018, 32, (12), 12435-15-12446.

102. Grigsby, R. D.; Green, J. B., High-resolution mass spectrometric analysis of a vanadyl porphyrin fraction isolated from the $>700 \mathrm{C}$ resid of Cerro Negro heavy petroleum. Energy Fuels 1997, 11, (3), 60262-609.

103. Rodgers, R. P.; Marshall, A. G., Petroleomics: Advanced Characterization of Petroleum-Derived Materials Characterized by Fourier Transform Ion Cyclotron Resonance Mass Spectrometry (FT-ICR MS). In Asphaltenes, Heavy Oils and Petroleomics, Mullins, O. C.; Sheu, E. Y.; Hammami, A.; Marshall, A. G., Eds. Springer: New York, 2007.

104. Rosell-Melé, A.; Carter, J. F.; Maxwell, J. R., High-performance liquid chromatography-mass spectrometry of porphyrins by using an atmospheric pressure interface. J. Am. Soc. Mass Spectrom. 1996, 7 , (9), 965-95-971.

105. Rosell-Mele, A.; Carter, J. F.; Maxwell, J. R., Liquid chromatography/Tandem mass spectrometry of free base alkyl porphyrins for the characterization of the macrocyclic substituents in components of complex mixtures. Rapid Commun. Mass Spectrom. 1999, 13, (7), 568-58-573.

106. Chen, X.; Zhang, Y.; Han, J.; Zhang, L.; Zhao, S.; Xu, C.; Shi, Q., Direct nickel petroporphyrin analysis through electrochemical oxidation in electrospray ionization ultrahigh-resolution mass spectrometry. Energy Fuels 2021, 35, (7), 5748-58-5757.

107. Purcell, J. M.; Hendrickson, C. L.; Rodgers, R. P.; Marshall, A. G., Atmospheric pressure photoionization Fourier transform ion cyclotron resonance mass spectrometry for complex mixture analysis. Anal. Chem. 2006, 78, (16), 5906-56-5912.

108. Purcell, J. M.; Hendrickson, C. L.; Rodgers, R. P.; Marshall, A. G., Atmospheric pressure photoionization proton transfer for complex organic mixtures investigated by Fourier transform ion cyclotron resonance mass spectrometry. J. Am. Soc. Mass Spectrom. 2007, 18, (9), 1682-12-1689.

109. Purcell, J. M.; Juyal, P.; Kim, D. G.; Rodgers, R. P.; Hendrickson, C. L.; Marshall, A. G., Sulfur speciation in petroleum:m : Atmospheric pressure photoionization or chemical derivatization and 
electrospray ionization Fourier transform ion cyclotron resonance mass spectrometry. Energy \& Fuels 2007, 21, (5), 2869-29-2874.

110. Purcell, J. M.; Rodgers, R. P.; Hendrickson, C. L.; Marshall, A. G., Speciation of nitrogen containing aromatics by atmospheric pressure photoionization or electrospray ionization Fourier transform ion cyclotron resonance mass spectrometry. J. Am. Soc. Mass Spectrom. 2007, 18, (7), 1265-15-1273.

111. Purcell, J. M.; Rodgers, R. P.; Hendrickson, C. L.; Marshall, A. G., Atmospheric Pressure Photoionization Proton Transfer for Complex Organic Mixtures Investigated by Fourier Transform Ion Cyclotron Resonance Mass Spectrometry. J. Am. Soc. Mass Spectrom. 2007, 18, 1682-12-1689.

112. Qian, K.; Edwards, K. E.; Siskin, M.; Olmstead, W. N.; Mennito, A. S.; Dechert, G. J.; Hoosain, N. E., Desorption and Ionization of Heavy Petroleum Molecules and Measurement of Molecular Weight Distributions. Energy Fuels 2007, 21, (2), 1042-12-1047.

113. McKenna, A. M.; Chacón-Patiño, M. L.; Weisbrod, C. R.; Blakney, G. T.; Rodgers, R. P., Molecularlevel characterization of asphaltenes isolated from distillation cuts. Energy Fuels 2019, Ahead of print.

114. Chacón-Patiño, M. L.; Nelson, J.; Rogel, E.; Hench, K.; Poirier, L.; Lopez-Linares, F.; Ovalles, C., Vanadium and nickel distributions in Pentane, In-between C5-C7 Asphaltenes, and heptane asphaltenes of heavy crude oils. Fuel 2021, 292, 120259.

115. Chacón-Patiño, M. L.; Moulian, R.; Barrère-Mangote, C.; Putman, J. C.; Weisbrod, C. R.; Blakney, G. T.; Bouyssiere, B.; Rodgers, R. P.; Giusti, P., Compositional Trends for Total Vanadium Content and Vanadyl Porphyrins in Gel Permeation Chromatography Fractions Reveal Correlations between Asphaltene Aggregation and Ion Production Efficiency in Atmospheric Pressure Photoionization. Energy FUels 2020, 34, (12), 16158-18-16172.

116. Martinez-Haya, B.; Hortal, A. R.; Hurtado, P.; Lobato, M. D.; Pedrosa, J. M., Laser desorption/ionization determination of molecular weight distributions of polyaromatic carbonaceous compounds and their aggregates. J. Mass Spectrom. 2007, 42, 701-71-713.

117. Cho, Y.; Witt, M.; Jin, J. M.; Kim, Y. K.; Nho, N.-S.; Kim, S., Evaluation of laser desorption ionization coupled to Fourier transform ion cyclotron resonance mass spectrometry to study metalloporphyrin complexes. Energy Fuels 2014, 28, (11), 6699-69-6706.

118. Kachadourian, R.; Srinivasan, N.; Haney, C.; Stevens, R. D., An LDI-TOF and ESI mass spectrometry study of a series of $\beta$-substituted cationic metalloporphyrins. J. Porphyrins Phthalocyanines 2001, 5, 507-57-511.

119. Xu, H.; Yu, D.; Que, G., Characterization of petroporphyrins in Gudao residue by ultraviolet-visible spectrophotometry and laser desorption ionization-time of flight mass spectrometry. Fuel 2005, 84, 647-67652.

120. McCarley, T. D.; McCarley, R. L.; Limbach, P. A., Electron-transfer ionization in matrix-assisted laser desorption/ionization mass spectrometry. Anal. Chem. 1998, 70, 4376-46-4379.

121. Ramírez-Pradilla, J. S.; Blanco-Tirado, C.; Combariza, M. Y., Electron-Transfer Ionization of Nanoparticles, Polymers, Porphyrins, and Fullerenes Using Synthetically Tunable $\alpha$ Cyanophenylenevinylenes as UV MALDI-MS Matrices. ACS Appl. Mater. Interfaces 2019, 11, 10975-1510987.

122. Giraldo-Dávila, D.; Chacón-Patiño, M. L.; Ramirez-Pradilla, J. S.; Blanco-Tirado, C.; Combariza, M. Y., Selective ionization by electron-transfer MALDI-MS of vanadyl porphyrins from crude oils. Fuel 2018, 226, 103-13-111.

123. Ramírez-Pradilla, J. S.; Blanco-Tirado, C.; Hubert-Roux, M.; Giusti, P.; Afonso, C.; Combariza, M. Y., Effect of the ionization sources on the targeted analysis of Nickel and Vanadyl Porphyrins in crude oil. Energy Fuels 2021, submitted.

124. Hay, B. P., Methods for molecular mechanics modeling of coordination compounds. Coord. Chem. Rev. 1993, 126, (1-21-2), 177-27-236. 
125. Kingsbury, C. J.; Senge, M. O., The shape of porphyrins. Coord. Chem. Rev. 2021, 431, 213760.

126. Rio, Y.; Rodríguez-Morgade, M. S.; Torres, T., Modulating the electronic properties of porphyrinoids: A voyage from the violet to the infrared regions of the electromagnetic spectrum. Org. Biomol. Chem. 2008, 6, (11), 1877-17-1894.

127. De Visser, S. P.; Stillman, M. J., Challenging density functional theory calculatins wth hemes and porphyrins. Int. J. Mol. Sci. 2016, 17, (4), 519.

128. Kaplan, W. A.; Suslick, K. S.; Scott, R. A., Core Size and Flexibility of Metallohydroporphyrin Macrocycles. Implications for F430 Coordination Chemistry. Journal of the American Chemical Society 1991, 113, (26), 9824-94-9827.

129. Munro, O. Q.; Bradley, J. C.; Hancock, R. D.; Marques, H. M.; Marsicano, F.; Wade, P. W., Molecular mechanics study of the ruffling of metalloporphyrins. J. Amer. Chem. Soc. 1992, 114, 7218-787230 .

130. Marques, H. M.; Munro, O. Q.; Grimmer, N. E.; Marsicano, F.; Pattrick, G.; Markoulides, T., A Force Field for Molecular Mechanics Studies of Iron Porphyrins. J. Chem. Soc. Faraday Trans. 1995, 91, (9).

131. Munoz, G. K.; Gunessee, B.; Bégué, D.; Bouyssiere, B.; Baraille, I.; Vallverdu, G.; Silva, H. S., Redox activity of nickel and vanadium porphyrins: A possible mechanism behind petroleum genesis and maturation? RSC Advances 2019, 9, (17), 9509-99-9516.

132. Kadiev, K. M.; Gyul'maliev, A. M.; Khadzhiev, S. N., Quantum-Chemical Modeling of Strength of Organometallic Bonds in Oil. Pet. Chem. 2015, 55, (8), 609-69-617.

133. Song, X.-Z.; Jaquinod, L.; Jentzen, W.; Nurco, D. J.; Jia, S.-L.; Khoury, R. G.; Ma, J.-G.; Medforth, C. J.; Smith, K. M.; Shelnutt, J. A., Metal dependence of the contributions of low-frequency normal coordinates to the sterically induced distortions of meso-dialkyl-substituted porphyrins. Inorg. Chem. 1998, 37, (8), 2009-29-2019.

134. Skopec, C. E.; Robinson, J. M.; Cukrowski, I.; Marques, H. M., Using Artificial Neural Networks to Develop Molecular Mechanics Parameters for the Modelling of Metalloporphyrins. III. Five Coordinate Zn(II) Porphyrins and the Metalloprophyrins of the Early 3d Metals. . J. Mol. Struc. 2005, 738, (1), 67-7778.

135. Marques, H. M.; Brown, K. L., Molecular mechanics and molecular dynamics simulations of porphyrins, metalloporphyrins, heme proteins and cobalt corrinoids. Coord. Chem. Rev. 2002, 225, (1), 12313-158.

136. Cundari, T. R.; Saunders, L.; Sisterhen, L. L., Molecular modeling of vanadium-oxo complexes. A comparison of quantum and classical methods. J. Phys. Chem. 1998, 102, (6), 997-17-1004.

137. Stoll, L. K.; Zgierski, M. Z.; Kozlowski, P. M., Density Functional Theory Analysis of Nickel Octaethylporphyrin Ruffling. J. Phys. Chem. A 2002, 106, (1), 170-10-175.

138. Czader, A.; Czernuszewicz, R. S., Fingerprinting petroporphyrin structures with vibrational spectroscopy. Part 7. Calculations using density functional theory of the molecular structures and structuresensitive vibrational modes of type II nickel(II) cycloalkanoporphyrins. Org. Geochem. 2007, 38, 250-20266.

139. Stoyanov, S. R.; Yin, C.-X.; R.G., M.; M.S., J.; Gusarov, S.; Kovalenko, A., Density functional theory investigation of the fffect of axial coordination and annelation on the absorption spectroscopy of nickel(II) and vanadyl porphyrins relevant to bitumen and crude oils. Can. J. Chem. 2013, 91, (9), 872-878. 140. Santos Silva, H.; Sodero, A. C. R.; Korb, J.-P.; Alfarra, A.; Giusti, P.; Vallverdu, G.; Bégué, D.; Baraille, I.; Bouyssiere, B., The role of metallporphyrins on the physical-chemical properties of petroleum fluids. Fuel 2017, 188, 374-34-381.

141. Mousavi, M.; Hosseinnezhad, S.; Hung, A. M.; Fini, E. H., Preferential adsorption of nckel porphyrin to resin to increase asphaltene precipitation. Fuel 2019, 236, 468-48-479. 
142. Mousavi, M.; Fini, E. H., Non-covalent $\pi$-stacking interactions between asphaltene and porphyrins on surfaces and nanostructures with periodic DFT calculations. J. Chem. Inf. Model. 2020, 60, (10), 4856-464866.

143. da Costa, L. M.; Stoyanov, S. R.; Gusarov, S.; Tan, X.; Gray, M. R.; Stryker, J. M.; Tykwinski, R.; Carneiro, J. W.; Seidl, P. R.; Kovalenko, A., Density Functional Theory investigation of the contributions of $\mathrm{pi}=$ pi stacking and hydrogen-bonding interactions to the aggregation of model asphaltene compounds. Energy \& Fuels 2012, Ahead of print.

144. Santos Silva, H. A., A.; Vallverdu, G.; Bégué, D.; Bouyssiere, B.; Baraille, I., , Impact of H-Bonds and Porphyrins on Asphaltene Aggregation As Revealed by Molecular Dynamics Simulations. Energy Fuels 2018, 32, (11), 11153-13-11164.

145. Silva, H. S.; Alfarra, A.; Vallverdu, G.; Bégué, D.; Bouyssiere, B.; Baraille, I., Role of the porphyrins and demulsifiers in the aggregation process of asphaltenes at water/oil interfaces under desalting conditions:

A molecular dynamics study. Pet. Sci. 2020, 17, 797-810

146. Gruden-Pavlović, M.; Grubišić, S.; Zlatar, M.; Niketić, S. R., Molecular mechanics study of nickel(II)octaethylporphyrin adbsored on graphite(0001). Int. J. Mol. Sci. 2007, 8, (8), 810-80-829.

147. Zaragoza, I. P.; Santamaria, R.; Salcedo, R., The interaction of vanadyl porphyrin with the HY Zeolite surface. J. Mol. Catal. A-Chem. 2009, 307, (1).

148. Torres, A.; Amaya Suárez, J.; Remesal, E.; Márquez, A. M.; Fernández Sanz, J.; Rincón Cañibano, C., Adsorption of prototypical asphaltenes on silica: First-principles DFT simulations including dispersion corrections. J. Phys. Chem. B 2018, 122, (2), 618-68-624.

149. Chilukuri, B.; Mazur, U.; Hipps, K. W., Structure, properties, and reactivity of porphyrins on surfaces and nanostructures with periodic DFT calculations. Appl. Sci. 2020, 10, (3), 740.

150. Myradalyyev, S.; Limpanuparb, T.; Wang, X.; Hirao, H., Comparative Computational Analysis of Binding Energies Between Several Divalent First-Row Transition Metals (Cr2+, Mn2+, Fe2+, Co2+, Ni2+, and $\mathrm{Cu} 2+$ ) and Ligands (porphine, Corrin, and TMC). Polyhedron 2013, 52, 96-16-101.

151. Ju, L.; Liu, T.; Lu, J.; Zhou, Y.; Wei, Q.; Li, S.; Ding, S.; Zhang, Y.; Shi, Q., Transformation of nickel octaethylporphrine in hydrodemetallization reactions. Energy Fuels 2016, 30, (9), 6933-63-6941.

152. Li, Y.; Shang, H.; Zhang, Q.; Elabyouki, M.; Zhang, W., Theoretical study of the structure and properties of Ni/V porphyrins under microwave electric field: A DFT study. Fuel 2020, 278, 118305.

153. García-Cruz, I.; Martínez-Magadán, J. M.; Alvarez-Ramirez, F.; Salcedo, R.; Illas, F., Theoretical study of nickel porphyrinate derivatives related to catalyst dopant in the oil industry. J. Mol. Catal. A-Chem. 2005, 228, (1), 195-25-202.

154. Salcedo, R.; Martínez, L. M. R.; Martínez-Magadán, J. M., Theoretical study of high-valent vanadium oxo-porphyrins as a dopant of crude oil. J. Mol. Struc-THEOCHEM 2001, 542, (1), 115-15-121. 155. Soret, J.-L., Analyse spectrale: Sur le specre d'absorption du sang dans la partie violette et ultraviolette. Comptes rendu de l'Academie des sciences 1883, 97, 1269-19-1273.

156. Speight, J. G., The Desulfurization of Heavy Oils and Residua. 2nd ed.; Marcel Dekker, Inc.: New York, 2000; Vol. 78.

157. Speight, J., Handbook of petroleum analysis John Wiley \& Sons. 2001; p 232-22-233.

158. Speight, J. G., Handbook of petroleum product analysis. John Wiley \& Sons: 2015.

159. Wei, W.; Bennett, C. A.; Tanaka, R.; Hou, G.; Klein, M. T., Detailed kinetic models for catalytic reforming. Fuel Process.Technol. 2008, 89, (4), 344-34-349.

160. Zheng, F., Molecular composition and structure of metal compounds in asphaltene. China University of Petroleum Beijing, Beijing. 2021.

161. Bai, P.; Etim, U. J.; Yan, Z.; Mintova, S.; Zhang, Z. G.; Zhong, Z.; Gao, X., Fluid catalytic cracking technology: current status and recent discoveries on catalyst contamination. Catalysis Reviews 2019, 61, (3), 333-43-405. 
162. Vogt, E. T. C.; Weckhuysen, B. M., Fluid catalytic cracking: recent developments on the grand old lady of zeolite catalysis. Chem. Soc. Rev. 2015, 44, (20), 7342-72-7370.

163. YangDong, X.; YuanBin, Y.; Ying, Z.; Huang, K. Q., Tackling high nickel feedstock. Hydrocarb. Eng. 2020, 25, (11), 19-29-22.

164. Liu, T., Transformation of metal compounds in the vacuum residuum hydrodemetallization and design of HDM catalysts. China University of Petroleum Beijing, Beijing. 2016.

165. Ali, M. F.; Abbas, S., A review of methods for the demetallatization of residual fuel oils. Fuel Process.Technol. 2006, 87, (7), 573-53-584.

166. Rodríguez, E.; Félixa, G.; Ancheyta, J.; Trejo, F., Modeling of hydrotreating catalyst deactivation for heavy oil hydrocarbons. Fuel 2018, 225, 118-18-133.

167. Sullivan, R. F.; Boduszynksi, M. M.; Fetzer, J. C., Molecular-transformations in hydrotreating and hydrocracking. Energy Fuels 1989, 3, (5), 603-63-612.

168. Topsoe, H.; Bjerne, C. S.; Massoth, F. E., Hydrotreating Catalysis: Science and Technology. Springer-Verlag: New York, 1996; Vol. 11, p 1-31-310.

169. Wiwel, P.; Knudsen, K.; Zeuthen, P.; Whitehurst, D., Assessing compositional changes of nitroge compounds during hydrotreating of typical diesel range gas oils using a novel preconcentration technique coupled with gas chromatography and atomic emission detection. Ind. Eng. Chem. Res. 2000, 39, (2), 53353-540.

170. Fish, R. H.; Komlenic, J. J.; Wines, B. K., Characterization and comparison of vanadyl and nickel compounds in heavy crude petroleums and asphaltenes by reverse-phase and size-excluded liquid chromatography/graphite furnace atomic absorption spectrometry. Anal. Chem. 1984, 56, 2452-22-2460. 171. Yen, T. F., The Role of Trace Metals in Petroleum. In Yen, T. F., Ed. Ann Arbor Science: Ann Arbor, MI, 1975.

172. Dickson, F. E.; Kunesh, C. J.; McGinnis, E. L.; Petrakis, L., Use of electron spin resonance to characterize the vanadium(IV)-sulfur species in petroleum. Anal. Chem. 1972, 44, (6), 978-98-981.

173. Yen, T. F., Characterization of parts of vanadyl non-porphyrins in petroleum. Acta Petrolei Sinica (Petroleum Processing Section) 1975, 36, (5), 1003-13-1010.

174. Wu, Y.; Zheng, F.; Lu, J.; Shi, Q., Characterization of parts of vanadyl non-porphyrins in petroleum. Acta Petrolei Sinica (Petroleum Processing Section) 2020, 36, (5), 1003-13-1010.

175. Moulian, R.; Zheng, F.; Salvato Vallverdu, G.; Barrere-Mangote, C.; Shi, Q.; Giusti, P.; Bouyssiere, B., Understanding the vanadium-asphaltene nanoaggregate link with silver triflate complexation and GPC ICP-MS analysis. Energy Fuels 2020, 34, (11), 13759-19-13766.

176. Zheng, F.; Zhang, Y.; Zhang, Y.; Han, Y.; Zhang, L.; Bouyssiere, B.; Shi, Q., Aggregation of petroporphyrins and fragmentation of porphyrin ions: Characterized by TIMS-TOF MS and FT-ICR MS. Fuel 2021, 289, 119889.

177. Wu, Y., Molecular composition of petroleum non-porphyrin. China University of Petroleum Beijing, Beijing. 2017.

178. Dominguez, G., December 17, 2014.

179. Charrie-Duhaut, A.; LEmoine, S.; Adam, P.; Connan, J.; Albrecht, P., Abiotic oxidation of petroleum bitumens under natural conditions. Org. Geochem. 2000, 31, (10), 977-17-1003.

180. Ocampo, R.; Riva, A.; Trendel, J. M.; Riolo, J.; Callot, H. J.; Albrecht, P., Petroporphyrins as biomarkers in oil-oil and oil-source rock correlations. Energy Fuels 1993, 7, (2), 191-11-193.

181. Blumer, M., Separation of porphyrins by paper chromatography. Anal. Chem. 1956, 28, (11).

182. Barwise, A. J. G., Role of nickel and vanadium in petroleum classification. Energy Fuels 1990, 4, (6), 647-67-652.

183. Szymczak-Zyla, M.; Kowalewska, G.; Louda, J. W., Chlorophyll- $a$ and derivatives in recent sediments as indicators of productivity and depositional conditions. Mar. Chem. 2011, 125, 39-49-48. 
184. Kashiyama, Y.; Ogawa, N. O.; Shiro, M.; Tada, R.; Kitazato, H.; Ohkouchi, N., Reconstruction of the biogeochemistry and ecology of photoautotrophs based on the nitrogen and carbon isotopic compositions of vanadyl porphyrins from Miocene siliceous sediments. Biogeosciences Discuss. 2008, 5, 361-41-409.

185. Keely, B. J.; Prowse, W. G.; Maxwell, J. R., The Treibs hypothesis: An evaluation based on structural studies. Energy Fuels 1990, 4, (6), 628-68-634.

186. Fookes, C. J. R., Structure determination of nickel(II) deoxophylloerythroetioporphyrin and a C30 homologue from an oil shale: Evidence that petroporphyrins are derived from chlorophyll. J. Chem. Soc.

Chem. Comm. 1983, 1472-12-1473.

187. Gibbison, R.; Peakman, T. M.; Maxwell, J. R., Novel porphyrins as molecular fossils for anoxygenic photosynthesis. Tetrahedron Lett. 1995, 36, 9057-97-9060.

188. Kashiyama, Y.; Shiro, M.; Tada, R.; Ohkouchi, N., A novel vanadyl alkylporphyrins from geological samples: a possible derivative of divinylchlorophylls or bacteriochlorophyll a. Chem. Lett. 2007, 36, 706-76707.

189. Kashiyama, Y.; Ogawa, N. O.; Kuroda, J.; Shiro, M.; Nomoto, S.; Tada, R.; Kitazato, H.; Ohkouchi, N., Diazotrophic cyanobacteria as the major photoautotrophs during mid- Cretaceous oceanic anoxic events: nitrogen and carbon isotopic evidence from sedimentary porphyrin. Org. Geochem. 2008, 39, (5), 532-52549 .

190. Keely, B. J.; Brereton, R. G.; Maxwell, J. R., Porphyrin and chlorin distributions in a Lake Pliocene lacustrine sediment. Geochim. Cosmochim. Acta 1994, 58, 3691-31-3701.

191. Boreham, C. J.; Fookes, C. J. R.; Popp, B. N.; Hayes, J. M., Origins of etioporphyrins in sediments: evidence from stable carbon isotopes. Geochim. Cosmochim. Acta 1989, 53, 2451-21-2455.

192. Boreham, C. J.; Fookes, C. J. R.; Popp, B. N.; Hayes, J. M., Origin of petroporphyrins. 2. Evidence from stable isotopes. Energy Fuels 1990, 4, 658-68-661.

193. Chicarelli, M. I.; Hayes, J. M.; Popp, B. N.; Eckardt, C. B.; Maxwell, J. R., Carbon and nitrogen isotopic compositions of alkyl porphyrins from the Triassic Serpiano oil shale. Geochim. Cosmochim. Acta 1993, 57, 1307-17-1311.

194. Kashiyama, Y.; Kitazato, H.; Ohkouchi, N., An improved method for isolation and purification of sedimentary porphyrins by high-performance liquid chromatography for compound specific isotopic analysis. J. Chromatogr. A 2007a, 1138, 73-83-83.

195. Boggess, J. M.; Czernuszewicz, R. S.; Lash, T. D., Fingerprinting petroporphyrin structures with vibrational spectroscopy. Part 6. resonance Raman characterization of regioisomets of nickel(II) benzoetioporphyrin. Org. Geochem. 2002, 33, 1111-11-1126.

196. Gueneli, N.; McKenna, A. M.; Ohkouchi, N.; Boreham, C. J.; Beghin, J.; Javaux, E. J.; Brocks, J. J., 1.1-Billion-Year-Old Porphyrins Establish a Marine Ecosystem Dominated by Bacterial Primary Producers. Proc. Nat. Acad. Sci. 2018, 115, (30), E6978-E6986.

197. Grosjean, E.; Adam, P.; Connan, J.; Albrecht, P., Effects of weathering on nickel and vanadyl porphyrins of a Lower Toarcian shale of the Paris basin. Geochim. Cosmochim. Acta 2004, 68, (4). 198. Zheng, F.; Zhu, G. Y.; Chen, Z.-Q.; Shi, Q., Molecular composition of vanadyl porphyrins in the gilsonite. J. Fuel Chem. Technol. 2020, 48, (5), 562-52-567.

\section{FIGURE LEGENDS}

\section{Figure 1.}

Figure 2.

Figure 3. 
Figure 4.

Figure 5.

Figure 6. 